\title{
VIOLENCIA Y SOCIEDAD EN UNA VILLA MEDIEVAL: CASTELLÓN DE LA PLANA EN EL SIGLO XV
}

\author{
PAu Viciano \\ Universitat de València
}

RESUMEN: A partir de los registros judiciales locales, este artículo estudia el modelo de violencia en una pequeña ciudad valenciana orientada, en gran medida, a las actividades agrarias. Se trataba sobre todo de una violencia estructural y cotidiana, que babitualmente no era provocada por delincuentes profesionales, sino por gente común e incluso por miembros del grupo dirigente. El abuso de la fuerza solía producirse desde los poderosos hacia los débiles (de ricos a pobres, de amos a criados, de maridos a mujeres, de cristianos a musulmanes) de manera que estas formas de violencia reafirmaban las jerarquías internas que dividían a la comunidad local.

Palabras clave: Valencia. Edad Media. Violencia. Criminalidad. Pequeñas ciudades.

\begin{abstract}
On the evidence of local court rolls, this paper studies the patters of violence in a valencian small town oriented to a great extent toward agrarian activities. It was especially a structural and daily violence, that usually it was not caused by habitual criminals but by common people and even by members of the ruling group. Abuse of force usually taked place from poweful to weak (from richs to poors, from masters to serviants, from husbands to wives, from christians to muslims), so that these forms of violence reaffirmed internal hierarchies that divided local community.
\end{abstract}

KEY WORDS: Kingdom of Valencia. Middle Ages. Violence. Criminality. Small towns.

Desde la guerra a los levantamientos populares, las luchas de facciones o la persecución de minorías religiosas, la violencia se mostraba permanente y multiforme en las sociedades tardomedievales. Pero más allá de estos acontecimientos traumáticos, y en cierta manera extraordinarios, existía una violencia cotidiana, que surgía de las tensiones latentes en el seno de una comunidad 
local $^{1}$. No se trataba sólo de las formas de criminalidad protagonizadas, sobre todo en las grandes ciudades, por elementos marginales y delincuentes profesionales, sino de los enfrentamientos y estallidos de cólera de gente común y, a menudo, de vecinos respetables e integrados en la sociedad política de comunidades rurales y pequeños núcleos urbanos. El estudio de un espacio local concreto, Castellón de la Plana en el siglo XV, permite aproximarse al modelo de violencia que caracterizaba a las villas valencianas y, en buena medida, al resto de las poblaciones catalano-aragonesas, en el contexto social y político de la constelación de pequeñas ciudades, villas y burgos, que tejían una espesa trama urbana —o semiurbana, si se quiere - extendida desde el Mediterráneo peninsular hasta el sur de Francia e Italia ${ }^{2}$. Con un millar de fuegos a principios del siglo XV, Castellón era una destacada villa real que, a pesar de ejercer unas innegables funciones urbanas — sobre todo mercantiles y administrativas-, conservaba un marcado tono rural, como consecuencia del predominio de los labradores entre sus vecinos ${ }^{3}$.

En los registros documentales del justicia de Castellón, el juez real ordinario de la villa ${ }^{4}$, se ha conservado información sobre 401 delitos denunciados o

${ }^{1}$ Para una aproximación de conjunto, centrada en la Inglaterra de los siglos XII-XV, pueden verse los trabajos reunidos en KAEUPER, Richard (ed.): Violence in Medieval Society, Woodbridge, 2000, que tratan aspectos tan diversos del fenómeno como el código caballeresco, la violencia política y doméstica, y las resistencias campesinas. Puede verse una reflexión crítica sobre las formas y la función social de la violencia, a partir de diversos casos europeos, en ALFONSO, Isabel, "Los nombres de la violencia y el control de su legitimación», Hispania, 61/2, 208 (2001), págs. 691706. En el ámbito hispánico pueden citarse obras colectivas recientes que abarcan también un amplio espectro de manifestaciones de la violencia, como IgLESIA, José Ignacio de la (coord.), Conflictos sociales, políticos e intelectuales en la España de los siglos XIV y XV, Logroño, 2004, y MUNITA, José Antonio (coord.): Conflicto, violencia y criminalidad en Europa y América, Bilbao, 2004, así como la síntesis de VAL VALDIVIESO, M. ${ }^{a}$ Isabel del: «Conflictividad social en la Castilla del siglo XV», en Homenatge a la Prof. Dra. Carme Batlle i Gallart, Acta Mediaevalia, 26 (2005), págs. 1033-1049.

2 El marco local ha servido también, en el caso castellano, para efectuar aproximaciones como las de CRUCES, Esther, "Orden público y violencia en la ciudad de Málaga a fines del siglo XV y principios del XVI (1495-1516)», Meridies, 2 (1995), págs. 121-143, y de MARTín CEA, Juan Carlos: «Violencia y conflictividad social en Castilla vista desde el prisma de la historia local (siglos XIV y XV)», en Munita, José Antonio (coord.): Conflicto..., op. cit., págs. 105-144, y desde una perspectiva territorial más amplia, destacan trabajos como el de BAZÁN, Iñaki: Delincuencia y criminalidad en el País Vasco en la transición de la edad media a la moderna, Vitoria-Gasteiz, 1995. Sobre el conjunto catalano-aragonés, puede verse la síntesis de NARBONA, Rafael: «La conflictividad social en las ciudades de la Corona de Aragón (siglos XIV-XV)», en MuniTA, José Antonio (coord.), Conflicto..., op. cit., págs. 79-104.

${ }^{3}$ La villa era sede de una delegación del gobernador del reino de Valencia y constituía un centro comercial — disponía de un pequeño puerto y de una feria — que proyectaba su influencia en las comarcas valencianas septentrionales. El relieve de las funciones urbanas y agrarias de la población se analiza en VicianO, Pau: «Marché du crédit et structuration de l'espace rural. Le Pays Valencien au XV siècle», Histoire et Sociétés Rurales, 21 (2004), págs. 11-38.

${ }^{4}$ Sobre los aspectos institucionales del oficio de justicia, puede verse la obra clásica de RocA, Francisco A., El justicia de Valencia, 1238-1321, Valencia, 1970, y el artículo de NARBONA, Rafael, 
castigados entre 1416 y 1495 . Se trata sobre todo -298 casos- de multas impuestas por este oficial ${ }^{5} \mathrm{y}$, en menor medida - 103 casos_-, de denuncias y otras diligencias procesales asentadas en los libros de la corte del justicia ${ }^{6}$. Del total de delitos, 153 casos, es decir, el 38,15\% correspondía a hechos violen$\operatorname{tos}^{7}$. Estos incidentes incluyen agresiones físicas —armadas o no- y esgrimir armas en el transcurso de un enfrentamiento (treta d'armes), aunque no se hiciese uso de ellas. En cambio, no se han considerado en esta categoría de delitos las agresiones verbales —insultos e injurias ${ }^{8}$ — $(7,48 \%)$ ni la simple posesión de armas prohibidas $(6,73 \%)$, si no se habían exhibido amenazadoramente. Sólo las infracciones por el juego $(24,43 \%)$ y las blasfemias $(15,46 \%)$ tenían una presencia remarcable entre las transgresiones perseguidas por el justicia local, mientras que los delitos contra la propiedad eran insignificantes $(1,49 \%)$. Este modelo de criminalidad, con un claro predominio de la violencia sobre el robo, acercaría el caso valenciano a otra región mediterránea como Provenza, mientras que se alejaría de las pequeñas ciudades inglesas del siglo XIV, donde los delitos contra la propiedad superaban a las agresiones contra las personas ${ }^{9}$. En este sentido, conviene precisar que, en el caso de Castellón, sólo se han considerado como robos aquellas transgresiones denunciadas ante el justicia como verdaderos delitos de carácter criminal $^{10}$, pero no se han contabilizado los pe-

«El justicia criminal. Una corte medieval valenciana, un procedimiento judicial», Estudis Castellonencs, 3 (1986), págs. 287-370. Sobre el justicia de Castellón, es de utilidad el estudio introductorio del libro de Magdalena, José Ramón: Judíos y cristianos ante la «cort del justícia» de Castellón, Castellón, 1988.

5 Archivo del Reino de Valencia (ARV), Maestre Racional, 6.941 (año 1416), 6.942 (1419), 6.945 (1437), 6.947 (1444), 6.948 (1446), 6.949 (1467), 6.950 (1475), 6.951 (1477), 6.952 (1482) y 6.953 (1484).

6 Archivo Municipal de Castellón (AMC), Cort del Justícia (CJ), años 1439, 1441, 1442, 1445, $1447,1448,1454,1455,1456,1465,1466,1467,1483,1485,1491,1492$ у 1495.

7 El total de 153 casos de violencia se desglosaba de la siguiente manera: 106 multas y 47 denuncias y otras diligencias judiciales.

${ }^{8}$ Lo que no significa que este tema, junto con las agresiones menores, carezca de relevancia, como puede verse en el estudio de MADERO, Marta: Manos violentas. Palabras vedadas. La injuria en Castilla y León (siglos XIII-XIV), Madrid, 1992.

9 En la ciudad de Aviñón los delitos violentes suponían un $60 \%$ de los castigados con multas en la ciudad y un $40 \%$ en los lugares rurales de la zona, cf. CHIFFOLEAU, Jacques: Les justices du Pape. Délinquance et criminalité dans la région d'Avignon au quatorzième siècle, París, 1984, págs. 103112. También en Marsella, en 1330-1331, los actos violentos —incluyendo amenazar con armasrepresentaban el 58,7 \% de los delitos, mientras que los robos sólo ascendían al 4,5\%, según SMAIL, Daniel L., "Common violence: vengeance and inquisition in fourteenth-century Marseille», Past and Present, 151 (1996), pp. 28-59. En las comunidades rurales inglesas los delitos contra la propiedad ascendían casi a un $80 \%$ de las denuncias, según HANAWALT, Barbara A.: Crime and conflict in English communities, 1300-1348, Cambridge (Mass.), 1979, págs. 65-68. Otros estudios también destacan el predomonio del robo en el mundo tardomedieval, vid. WEISSER, Michael R.: Crime and punishment in early modern Europe, Brighton, 1982, págs. 29-49.

${ }^{10}$ En este sentido, la discrecionalidad de los jueces era grande, ya que los Fueros de Valencia no especificaban el tipo de sustracción que debía considerarse como una infracción criminal, pero la 
queños hurtos de frutos o leña que simplemente infringían las ordenanzas municipales y que eran sancionados por los guardas rurales con una multa de escaso montante.

Los vecinos de Castellón recurrían con frecuencia a las manos y a las armas para zanjar sus conflictos. Ahora bien, bajo la calificación de «violencias» pueden considerarse agresiones de naturaleza y gravedad muy distinta. Dejando aparte la violencia institucional, representada especialmente por la tortura procesal y las penas corporales dictadas por el justicia, hay que diferenciar entre las peleas que estallaban de manera casual y los ataques premeditados - llevados a cabo acordadament, como decían los documentos - que a menudo se inscribían en el ciclo de venganzas que caracterizaban las luchas de bandos. Con mucho, las violencias más usuales eran las peleas espontáneas —un $90 \%$ de las agresiones-, que podían ir desde una riña callejera entre vecinas hasta incidentes graves, donde se esgrimían cuchillos y a veces se vertía sangre. En la mayoría de estos enfrentamientos casuales - en un $60 \%$ del total, protagonizados siempre por hombres - los implicados acababan amenazándose con armas, mientras que el resto de estas peleas se dirimían a golpes. En contraste con este trasfondo cotidiano, ocasionalmente —eran sólo un $10 \%$ del total de agresiones_, surgían asaltos premeditados contra víctimas desprevenidas, con una intención homicida $\mathrm{o}$, al menos, de causar daños graves. La documentación conservada en los registros del justicia, a pesar de su carácter fragmentario, permite una aproximación, incluso cuantitativa, a estos comportamientos agresivos en una pequeña ciudad de tonalidad rural, donde, lejos de visiones idílicas, vecinos de la más diversa condición social se veían implicados en incidentes violentos.

\section{TIEMPOS, LUGARES Y ACTITUDES}

Las denuncias, y menos aún las escuetas anotaciones de las multas, no permiten establecer con precisión qué momento del día era el más peligroso para circular por las calles o los caminos rurales de una villa como Castellón. La noche, ciertamente, tenía mala fama. La propia literatura de la época evocaba la

\footnotetext{
dureza de las penas que se especificaban —azotes y, en el caso de reincidencia, mutilación e incluso la pena de muerte- ya deja suponer que no se trataba de comer algunos frutos de un campo vecino o coger algún manojo de leña, que eran el tipo de transgresiones leves previstas en las ordenanzas municipales. De hecho, en estos textos legales, al tipificar este tipo de infracciones menores, nunca se hacía referencia a «hurtar» o «robar», sino a «tomar», «coger», «llevarse» o «comer». Si se consideran estos pequeños hurtos como delitos, los atentados contra la propiedad ascendirían al $88 \%$ de los «delitos» en años como 1446, ya que en el cuaderno de multas del justicia se registraron 132 sanciones por pequeños hurtos agrarios y sólo 20 por otros conceptos, cf. ARV, Maestro Racional, 6948. Sobre los Fueros, cf. TARAÇONA, Jeroni: Institucions dels furs y privilegis del regne de València, Valencia, 1580, y, respecto a las ordenanzas municipales, REVEST, Lluís (ed.): Libre de ordinacions de la vila de Castelló de la Plana, Castellón, 1957.
} 
llegada de las tinieblas como la hora de los malhechores y, de hecho, las autoridades municipales dictaban disposiciones para evitar los estallidos de violencia nocturna ${ }^{11}$. Cuando caía la noche, precisamente después del toque de la «campana del ladrón» (seny del lladre), se restringía la circulación por las calles oscuras de la villa ${ }^{12}$. Los noctámbulos que entraban y salían de tabernas y hostales, o que se adentraban en el burdel, tenían que llevar luces, sobre todo para ser reconocidos y no poder ocultar las posibles transgresiones en el anonimato. Los juglares y los grupos de jóvenes trasnochadores que se atrevían a bailar en la calle después de haber sonado el seny del lladre se exponían también a una multa, pero la pena más severa era contra los vecinos que fuesen tocando instrumentos por la noche o cantant la matinada, y ello no sólo por las molestias que podía causar el ruido, sino más bien para prevenir las peleas que podían derivarse de las provocaciones y burlas que proferían los que se detenían delante de alguna puerta tocando o cantando ${ }^{13}$. La mayor facilidad con que podían cometerse los robos de cosechas o los daños del ganado en los campos explica que normalmente las multas estipuladas en las ordenanzas municipales fuesen el doble de onerosas de noche que de día. Además, el propio justicia podía encabezar personalmente la ronda nocturna que recorría las calles de la villa para asegurar el orden, dispuesto a prender ladrones y otros malhechores y a confiscar las armas ilegales de los escasos vecinos que no dormían ${ }^{14}$. Pero a pesar del sentido amenazador que tenía la noche para la gente de aquella época, la mayoría de las agresiones denunciadas y castigadas parece que se producían a plena luz del día.

De una veintena de casos en que se precisa la hora o en que puede deducirse el momento de los hechos, sólo tres agresiones tuvieron lugar al declinar el día. Una al anochecer, cuando, acabada la jornada laboral, los vecinos, incluso los más prudentes, aún permanecían en la calle. Así, en 1441 Berenguer Moliner fue testigo de una pelea entre el hijo de En Giner y Vicent Sabater «bun vespre, ora de la oració, stant a la sua porta» ${ }^{15}$. Las otras dos agresiones se produjeron en plena noche. Una de ellas, la perpetrada en 1445 por Pere Antoni contra Francesc Gaçó, había sucedido «en ora acaptada, entre les nou e X ores de la nit», y la otra, de 1456, cuando Lluís Blasco atacó a Joan Barta, se produjo «de nit» ${ }^{16}$. En estos últimos casos las acciones eran premeditadas, y los acusados

${ }^{11}$ Sobre la vivencia de la noche en las pequeñas comunidades locales, cf. la aproximación pionera de Furió, Antoni y GarciA-Oliver, Ferran: «Del dia i la nit. Actituds i comportaments al món rural medieval valencià», L'Ullal, 9 (1986), págs. 42-52.

${ }_{12}$ Este toque corría a cargo del acólito (escolà) de la iglesia, pero cobraba su salario del justicia, que en 1416 gastó 15 sueldos por este concepto, ARV, Maestre Racional, 6.941.

${ }_{13}$ Sobre la obligación de llevar luces, cf. la ordenanza núm. 36 y para los bailes y canciones las 33 y 34, según REVEST, Lluís (ed.): Libre de ordinacions..., op. cit., págs. 49, 32 y 33, respectivamente.

${ }_{14}$ AMC, Llibre de Consells (LC) (1489-90), 3 de marzo de 1490, por lo que respecta a la detención de un ladrón; sobre la confiscación de armas pueden verse las multas de los libros del justicia.

15 AMC, CJ, 3 de abril de 1441.

16 AMC, CJ, 13 de noviembre de 1445 y 8 de noviembre de 1456. 
esperaron las sombras para buscar la impunidad, pero incluso la mayoría de las violencias calculadas tenían lugar de día ${ }^{17}$.

Los espacios violentos, en cambio, se conocen mejor. De los 153 incidentes documentados, se puede identificar el lugar donde se produjeron 34, es decir, un $22 \%$ del total $^{18}$. De entrada, a partir de los hechos castigados por el justicia, sería más peligrosa la villa, el interior de las murallas, que los campos de su término rural. Teniendo en cuenta que la mayoría de las agresiones eran simples peleas más o menos espontáneas, que estallaban con el contacto azaroso de los implicados - aunque solía existir entre ellos un conflicto latente-, se explica que los escenarios proclives a los altercados fuesen los lugares de sociabilidad más densa de la villa. Así, dos tercios de los espacios identificados se hallaban en el interior de la muralla, y de éstos, la mitad eran lugares públicos como las calles y la plaza mayor. La plaza, donde estaba la iglesia, el cementerio, las carnicerías y la sede de los diferentes poderes públicos, era el centro de reunión por excelencia de los habitantes y forasteros, pero la calle tampoco era una simple vía de paso, sino que los vecinos trabajaban o simplemente curioseaban en la puerta de las sus casas. Ahora bien, fue en el ámbito privado de la casa, del agresor o de la víctima, donde se cometió la otra mitad de las violencias acaecidas dentro de las murallas. Sólo en un caso se trataba de conflictos domésticos, de malos tratos infligidos por el marido a su mujer. La mayoría de los incidentes se habían producido en el domicilio del agredido, ya que se trataba de crímenes —incluyendo un homicidio - cometidos con premeditación. En 1467, por ejemplo, Pere Segarra havia denunciado a los hermanos Jaume, Guillem y Francesc Miquel, que «li vingueren, mà armada, a combatre la casa»y, en un caso más grave, de 1445, Pere Pomar fue asesinado mientras se encontraba convaleciente en su domicilio, «jahent malalt en son lit» ${ }^{19}$. En cambio, las violencias que habían surgido en la casa del atacante —una cuarta parte de las registradas en un lugar privado, algunas protagonizadas por mujeres- eran resistencias a los oficiales que se habían desplazado allí para reclamar el pago de multas o impuestos, lo cual había suscitado una fuerte discusión y la reacción agresiva del deudor o de alguno de sus vecinos. Espacios peligrosos por la afluencia de población flotante y de las actividades que en ellos se realizaban eran las tabernas, los hostales y el burdel. Hay constancia de la implicación de

17 De 16 agresiones premeditadas, 2 fueron de noche, 6 de día y 8 en un momento desconocido, pero teniendo en cuenta que la nocturnidad solía ser un agravante, el hecho de que los denunciantes no especifiquen la hora parece indicar que los hechos sucederían de día. En la región de Aviñón, durante el siglo XIV, tampoco puede afirmarse que la mayoría de los hechos violentos se produjesen de noche, cfr. Chiffoleau, Jacques: Les justices..., op. cit., págs. 140-144.

${ }_{18}$ Los lugares eran 7 en la casa de la víctima, 5 en la calle, 5 en un campo de la víctima, 4 en la plaza mayor, 3 en la casa de agresor, 3 en un camino, 2 en el campo, 1 en el domicilio conyugal, 1 en un corral, 1 en el juego del alfardo, 1 un terreno de pasto y 1 fuera de Castellón, en el lugar de Almassora.

19 AMC, CJ, 17 de agosto de 1467 y 16 de julio de 1445. 
algún posadero (hostaler) en hechos violentos, pero no puede asegurarse que hubiesen tenido lugar en su establecimiento. Las deliberaciones de los consejeros municipales, en cambio, sí que ponían de manifiesto la inseguridad del burdel de la villa, del que en 1478 de decía que «stava en loch molt perillós e que ja se havien seguits molts desastres, axí de nafres com de morts» ${ }^{20}$.

Una vez fuera de la muralla, el peligro residía en los caminos del término rural: 3 de los 11 ataques documentados en el campo tuvieron lugar en las vías de comunicación, donde coincidían al comenzar o acabar la jornada de trabajo los vecinos enemistados. Así, en 1441 la viuda de Antoni Valentí fue agredida por Miquel Cireró, «com venint de l'ort, lo dit Cireró la trobà en lo camí». Otras veces el encuentro no era casual, sino que el atacante estaba al acecho de la víctima, como sucedió, en 1439, en el caso de Pere Sala, ya que según Miquel Alegret, «li és exit al camí de Almaçora e l'a nafrat de bun colp mortal al coll $\rangle^{21}$. Sin embargo, la mayoría de las violencias cometidas en el campo se perpetraban en la heredad de la víctima. Se trataba siempre de ataques premeditados que sorprendían con su brutalidad — se denunciaban ante el justicia como intentos de homicidio- a los vecinos que estaban trabajando sus tierras. Era el caso de Francesc Feliu, cuando en 1455 denunció a Joan Tomàs, vecino de Borriol, porque «li sia vengut, cas acordat, en sa heretat por matar aquell... ell fent sa faena en lo dit mallol ab una exada» ${ }^{22}$. El campo era también el escenario del trabajo dependiente de criados que a menudo eran castigados por sus amos con una violencia que se juzgaba excesiva. En 1467, Jaume Cerdà golpeaba a una criada que tenía a su servicio mientras la joven «plegava palla per la era» en la partida de Fadrell ${ }^{23}$.

En general, antes de llegarse a las manos se pasaba por las palabras. No era extraño oír insultos en los juicios, pero más que una forma de agresión eran una protesta que expresaba el rechazo a lo que se consideraba una injusticia cometida por la falsedad del otro litigante o por la parcialidad o ineficacia del juez $^{24}$. En cambio, las injurias y los insultos precedían a menudo a las peleas que estallaban repentinamente. En 1441, Pere Alegre, antes de atacar con el puñal «vingué a noves ab lo dit en Cerdà»y, de la misma manera, antes de echar mano de sus cuchillos, en plena discusión por el juego del alfardo, Antoni Safont y Ramon Mallassén «sobre aquell joch agueren noves» ${ }^{25}$. Tampoco era sorprendente que la discusión provocase la reacción solidaria y violenta de los vecinos del implicado, como le sucedió al missatger Joan Roís, ya que, «venint a noves» con un deudor al que reclamaba cierto pago, tuvo que sufrir los golpes que le propinó Bartomeu Gisbert, que había salido de la casa vecina alertado

\footnotetext{
20 AMC, LC (1478-79), 16 de diciembre de 1478.

21 AMC, CJ, 18 de marzo de 1441 y 26 de septiembre de 1439, respectivamente.

22 AMC, CJ, 21 de marzo de 1455.

23 AMC, CJ, 22 de agosto de 1467.

24 Vid. Viciano, Pau: Poder municipal i grup dirigent local al País Valencià. La vila de Castelló de la Plana (1375-1500), Valencia, 1994, v. II, págs. 530-539, tesis doctoral (ed. en microficha, 1997).

25 AMC, CJ, 21 de abril y 12 de julio de 1441.
} 
por la discusión ${ }^{26}$. El insulto y la agresión física, sin embargo, no eran patrimonio exclusivo de los hombres. En 1485, en una reunión de vecinas que hilaban en la puerta de su casa, na Joana, acusada de robar un pollo por otra mujer, la descalificó afirmando: "yo us dic que·n mentiu». A continuación se entrometió una tercera, la mujer de Pere Granyana, atacándola verbalmente: «si vós bo déyeu a mi, ja us adobaria les orelles» y, ante su actitud amenazadora, na Joana replicó: «aquesta dona no està bé, que no he res ab ella». Eso fue suficiente para que la mujer de Granyana iniciase la pelea a golpes con el huso de hilar ${ }^{27}$. En otras ocasiones, las palabras y los gestos insultantes no eran tanto una reacción visceral como una acción calculada para provocar la pelea, normalmente — es obvio — cuando los agresores estaban organizados, bien armados y superaban en número a sus contrincantes. En 1441 se cruzaron por la calle Guillem Sastre, por una parte, y Pere Segarra y otros jóvenes, por la otra, y «en pasar-se la bu dels sobredits prop de l'altre, lo dit Pere Segara se decantàs devés lo dit Sastre, e encorvaren-se dels musclas, e lo Sastre dix al altre: "Axò no és cortesia" e l'altre respòs", dando lugar a un enfrentamiento verbal que pronto acabó a pedradas. Más grave fue la agresión que sufrió Pere Gaçó en 1445, cuando se le presentaron de noche Pere Antoni y otros dos «e allí en la sua porta, cridant-lo ab paraulas injurioses que bixqués e devallàs o que.s fes a la finestra, que.l clavarien ab la ballesta» ${ }^{28}$. De manera semejante, prevaleciéndose de su superioridad física y del hecho de ir armado, el labrador Miquel Cireró no dudó en insultar a Sibília Valentí, viuda de un zapatero, diciéndole: "Na vella bagassa, si vós fóseu home, ací u parlaríem vós e yo» y no contento con vejarla de palabra, "tornà dues vegades por donar-li ab la lança», para terminar amenazando a la viuda con que «si ella anave a l'alqueria, que ell la jaquiria al ba bun quantó del troç» ${ }^{29}$.

La exhibición de armas con frecuencia también constituía una provocación que podía desembocar en un enfrentamiento sangriento. Por ello los justicias vigilaban por la noche las calles de la villa y confiscaban las armas de los noctámbulos que estaban prohibidas. Sobre todo se trataba de espadas —-más de la mitad de los 27 casos documentados_-, y en menor medida de puñales de dimensiones o características ilegales. Sin embargo, no puede negarse que el arma más popular, al menos la que se llevaba de manera generalizada, era el cuchillo y, en segundo lugar, el puñal. De entrada, estas armas no eran ilícitas y ello explica que fuesen las que esgrimían mayoritariamente los agresores en las peleas y ataques. De un centenar de hechos armados que se denunciaron ante el justicia, en la mitad se indicaba el tipo de arma y, de éstos, en el $82 \%$ de los casos las que se habían utilizado eran cortas ${ }^{30}$. De hecho, sólo se tiene constancia de dos ataques con espada y de cuatro con lanza, que era el arma

${ }^{26}$ AMC, CJ, 16 de enero de 1495.

27 AMC, CJ, 26 de enero de 1485.

28 AMC, CJ, 26 de mayo de 1441 y 13 de noviembre de 1445.

29 AMC, CJ, 18 de marzo de 1441.

${ }^{30}$ De 97 agresiones armadas, en 50 se indica el tipo de arma: 30 cuchillos, 11 puñales, 4 lanzas, 2 ballestas, 1 espada, 1 dardo y 1 espada corta (basalart). 
más frecuente en los inventarios de bienes de los vecinos ${ }^{31}$, pero en estos últimos casos el agresor no hería con la punta sino golpeando con el asta. Más poder ofensivo tenían las armas arrojadizas como los dardos y, sobre todo, los passadors que disparaban las ballestas, pero es cierto que en los dos ataques en que se usaron no consiguieron alcanzar a las víctimas.

En general, en los enfrentamientos armados entre los vecinos no siempre se vertía sangre. Al contrario, sólo hay constancia de haberse provocado heridas en una quinta parte de las agresiones ${ }^{32}$. En este sentido, hay que subrayar que el $70 \%$ de los casos eran peleas espontáneas en que uno de los contrincantes llegaba a desenvainar el cuchillo, pero el hecho no pasaba de ahí por la intervención de los vecinos o del propio justicia, que imponía la pena por la treta d'armes al que primero las había esgrimido ${ }^{33}$. Cuando no se podían impedir las cuchilladas, las peleas podían acabar con un herido, aunque esto no llegaba a suceder ni en el $15 \%$ de estos incidentes armados. En cambio, los atacantes que se abalanzaban sobre la víctima de manera premeditada, a menudo valiéndose de la sorpresa - ab gran trayció, acordadament o sense dir res, como rezaba la documentación-y de su superioridad numérica o de armamento, eren los más eficaces para dañar a los adversarios: más de la mitad de los asaltos terminaron con heridos, de los cuales dos no tardaron en morir. Las víctimas de estos homicidios fueron el citado Pere Pomar — asesinado en su lecho de enfermoy Joan Belsa, «nafrat de dos colps en la cara» por Pere Sanou ${ }^{34}$. Así mismo, los ataques con ballesta y dardos, unas armas especialmente letales, se efectuaron de manera premeditada y con la intención - según los denunciantes- de matar. En este sentido, una buena prueba de la superioridad del equipamiento que podía reunir uno de estos agresores es el caso de Joan Tomàs, que se presentó por sorpresa en el campo de Francesc Feliu, que sólo podía defenderse con su azada, «per matar aquell ab spasa, broquer, punyal e lança» 35 .

La facilidad que tenían los vecinos comunes para acceder a las armas, sin duda, contribuía a incrementar la posibilidad de que las peleas acabasen con heridos. De hecho, los incidentes más incruentos eran los altercados sin armas, que normalmente se resolvían a base de bufets, grans colps ab les mans, a punyades o con algún tirón de cabellos ${ }^{36}$. Con todo, los vecinos iracundos también solían

31 Las lanzas suponían un $60 \%$ de las más de doscientas armas registradas en un centenar de inventarios. Cf. infra nota 35.

${ }_{32}$ De un total de 97 agresiones armadas (82 espontáneas y 15 premeditadas), sólo se produjeron heridos en 19 (11 espontáneas y 8 premeditadas), es decir, en un 19,5\% de los casos.

33 De un total de 82 casos de enfrentamientos espontáneos con armas, en 67 sólo se amenazó con usarlas (treta d'armes), mientras que se derramó sangre en 11 ocasiones; el resto fueron otro tipos de ataques sin heridos.

34 AMC, CJ, 16 de julio de 1445 y 26 de abril de 1455.

35 AMC, CJ, 21 de marzo de 1455. Hay que decir que la víctima sólo recibió «un colp ab la lança en lo cap e altre en lo braç».

36 Domingo Batle denunció a en Torrella, vaquero, «que.l havia pres dels cabells», AMC, CJ, 7 de abril de 1441 . 
echar mano de objetos contundentes como piedras, palos y, a veces, agredían a las víctimas con herramientas - un ligón, unas tijeras-, cañas o alguna botella. Así pues, no es extraño que se produjesen también heridos, pero sólo se han documentado dos en más de medio centenar de estas peleas. En 1439, por ejemplo, Bernat Porcar denunciaba a los hijos de Bernat Just, reclamándoles los daños y el importe de las medicinas, porque «li han abastonegat son fill e li han dat de grans colps al cap»37. La ausencia de sangre o de armas improvisadas, sin embargo, tampoco quitaba brutalidad a las palizas que los amos más violentos daban a sus jóvenes sirvientes. Fue el caso, ya citado, de Jaume Cerdà, que en 1467 «donà una gran punyada a la dita fadrina entre cap e coll e lançà-la en terra, e aprés amb la punta del peu li dava, e la dita fadrina cridava e por tota la partida la podien hoyr» 38 .

La mayoría de lo vecinos de la villa debían de estar armados. El cuchillo (coltell), estaba prácticamente ausente de los inventarios de bienes, pero con toda seguridad era el instrumento habitual, ya que al mismo tiempo de ser un arma servía para la caza y como utensilio de uso cotidiano. Sólo en los inventarios conservados en los libros de la corte del justicia, durante diez años comprendidos entre 1438 y 1456 , se citan más de doscientas armas ofensivas en manos de un centenar de vecinos, para una población que entonces se situaba en torno a los 600 fuegos. La defensa de la villa justificaba que los vecinos no sólo dispusiesen simplemente de cuchillos, sino también de armas de mayor capacidad ofensiva - de guerra - como lanzas, espadas, dardos y de instrumentos tan letales y sofisticados como las ballestas. Así, de las 210 armas identificadas, un $60 \%$ eran lanzas, el $18 \%$ espadas, el $12 \%$ ballestas y el $7 \%$ dardos ${ }^{39}$. Las propias autoridades municipales, como entrenamiento militar de los vecinos, incentivaban la práctica del tiro de ballesta, que tenía lugar en un descampado situado dentro de las murallas, en el ángulo suroeste ${ }^{40}$. Prueba de que el consejo no sólo toleraba la posesión de armas de guerra, sino que la protegía pensando en la defensa comunal, es la ordenanza que estipulaba que «negunes armes no sien venudes a bòmens stranys, ne las dites armes puxen ésser empenyorades por peyters», de manera que se prohibía así tanto su salida de la villa al venderse a forasteros como su pérdida por deudas ${ }^{41}$. Ahora bien, a pesar del

37 AMC, CJ, 16 de abril de 1439.

38 AMC, CJ, 22 de agosto de 1467.

39 En los 92 inventarios parciales o completos que se han conservado en los libros de la corte del justicia de 1438, 1439, 1441, 1442, 1445, 1447, 1448, 1454, 1455 y 1456, se registran un total de 123 lanzas, 37 espadas, 26 ballestas y 16 dardos, pero sólo de 6 puñales y 2 cuchillos.

40 El lugar se llamaba precisamente «pla de la Ballesteria», cf. la descripción del espacio urbano en SÁNCHEZ ADELL, José: «Paisaje urbano de una villa valenciana bajomedieval. (Notas y datos para una topografía de Castellón de la Plana, s. XIII-XV)», Boletín de la Sociedad Castellonense de Cultura, 66 (1990), págs. 291-332.

${ }_{41}$ El establiment es de 1389, núm. 83, publicado por Revest, Lluís (ed.), Libre de ordinacions..., op. cit., pág. 77. 
acceso que muchos vecinos tenían a las armas de guerra, no eran éstas las que se esgrimían en los incidentes cotidianos —sobre todo cuando no había premeditación-, sino los cuchillos y puñales que todo el mundo llevaba encima habitualmente como arma de defensa personal.

\section{LOS VECINOS VIOLENTOS}

Los agresores que se peleaban a golpes, esgrimían armas, provocaban heridas o incluso mataban en una villa como Castellón durante el siglo XV no eran forasteros, sino vecinos de la comunidad local ${ }^{42}$. Tampoco se trataba de una violencia marginal que surgiese de sectores depauperados, los que fluctuaban entre el trabajo precario y la desocupación, ni mucho menos de delincuentes de oficio u otros marginales. Este submundo propenso al robo y la agresión era característico sobre todo del paisaje social de las grandes ciudades ${ }^{43}$. Castellón, una villa de dimensiones medias, que vio como su población disminuía de un millar de fuegos a la mitad durante el siglo $\mathrm{XV}^{44}$, era sobre todo una comunidad de labradores propietarios, que representaban un $70 \%$ de los vecinos. La complejidad social era acusada, y aparte de los campesinos, existía un número destacado de artesanos — cerca del $20 \%$ de los fuegos-y algunos mercaderes y profesionales urbanos —alrededor del $7 \%$-, junto con un presencia apreciable de eclesiásticos —un $3 \%$ - y una minoría aristocrática, principalmente de origen burgués ${ }^{45}$. Sin embargo, a pesar de esta relativa complejidad social,

42 De 153 agresores, sólo había 5 que no eran de Castellón: 1 veneciano, 1 de Valencia, 1 de Onda, 1 de Borriol y un forastero sin más indicaciones, es decir, que suponían un escaso 3,2 \%.

${ }_{43}$ Cf. el estudio clásico de GeremeK, Bronislaw: Les marginaux parisiens aux XIV et $X V^{e}$ siècles, París, 1976, y, del mismo autor, Inutiles au monde. Truands et misérables dans l'Europe moderne (13501600), París, 1980. Sobre los problemas de convivencia entre los sectores populares de la ciudad, puede verse también de LeguAY, Jean-Pierre: «La criminalité en Bretagne au XV siècle: délits et répression», en La faute, la répression et le pardon, París, 1984, págs. 51-80 Para unos casos más próximos al de Castellón, cf. de ViNYOLES, Teresa-Maria: «La violencia marginal a las ciutats medievals (exemples a la Barcelona dels volts del 1400)», Revista d'Història Medieval, 1 (1990), págs. 155-177; SABATÉ, Flocel: «Orden y desorden. La violencia en la cotidianidad bajomedieval catalana», en Homenaje a la Prof. Carmen Orcástegui Gros, Aragón en la Edad Media, XIX-XV (1999), págs. 1389-1408, y, relativos a la ciudad de Valencia, los estudios de NARBONA, Rafael: Malhechores, violencia y justicia ciudadana en Valencia bajomedieval (1360-1399), Valencia, 1990, y Pueblo, poder y sexo. Valencia medieval (1306-1420), Valencia, 1992, y el libro de PÉrEZ GarCíA: Pablo, La comparsa de los malhechores. Un ensayo sobre la criminalidad y la justicia urbana en la Valencia preagermanada (1479-1518), Valencia, 1990. Sobre los mecanismos de iniciación en la delincuencia de sectores artesanales depauperados, ViCiANO, Pau: «Contrapunt. Rere les passes d'un lladre ajusticiat en la València fosca del segle XV», Afers, 46 (2003), págs. 619-661.

${ }^{44}$ GuINOT, Enric: «Demografia medieval del nord del País Valencià», en Estudis sobre la población del País Valencià, Valencia, 1988, págs. 229-249.

45 Según los datos de los padrones de la pecha de 1462, 1468, 1479 y 1497 estudiados en Viciano, Pau: Poder municipal..., op. cit., v. I, pág. 30. 
que distinguía a las villas de las poblaciones estrictamente rurales, no puede decirse que la población marginal, formada por peones sin calificación, pobres y vagabundos, tuviese unas dimensiones considerables. Estas «clases peligrosas», no eran responsables de los episodios de violencia que tenían lugar en la villa. Los agresores multados o denunciados ante el justicia se reclutaban sobre todo entre los labradores y artesanos que constituían la gran mayoría de la comunidad local. Sin embargo, existe una zona de sombra que puede distorsionar la interpretación de los datos socio-profesionales relativos a los atacantes. De un total de 153 agresores, se conoce el oficio de $89^{46}$, es decir, de un $60 \%$, mientras que del $40 \%$ no se ha podido identificar su adscripción profesional ni con los datos de la documentación primaria - multas y denuncias - ni con el vaciado de otras fuentes complementarias. Ahora bien, teniendo en cuenta la realidad sociológica de la villa, puede suponerse que la gran mayoría de estos vecinos, que el escribano del justicia identificaba sin necesidad de indicar su oficio, serían también labradores. De esta manera, en lugar de un $30 \%$, la participación de los labradores como atacantes debió de situarse alrededor del $70 \%$, una proporción igual a la que representaban en la estructura socio-profesional de la comunidad. Por su parte, los artesanos eran poco más del $20 \%$ de los agresores, una participación muy similar a su peso en el conjunto del vecindario.

\section{CUADRO 1: NIVEL SOCIO-PROFESIONAL DE LOS IMPLICADOS EN ACTOS VIOLENTOS}

\begin{tabular}{|c|c|c|}
\hline NIVEL SOCIOPROFESIONAL & AGRESORES (\%) & VÍCTIMAS (\%) \\
\hline labradores & $46(30,06)$ & $19(18,26)$ \\
\hline artesanos & $36(23,52)$ & $23(22,11)$ \\
\hline burgueses & $4(2,61)$ & $6(5,76)$ \\
\hline eclesiásticos & $1(0,65)$ & $1(0,96)$ \\
\hline criados & $2(1,30)$ & $14(13,46)$ \\
\hline marginados & - & $4(3,84)$ \\
\hline desconocido & $64(41,83)$ & $37(35,57)$ \\
\hline TOTAL & 153 & 104 \\
\hline
\end{tabular}

La distorsión más relevante entre la categoría profesional de los agresores y la del conjunto de los vecinos se encuentra en la escasa participación de los burgueses - mercaderes y profesionales urbanos - en los actos violentos, ya

${ }^{46}$ De los 85 agresores de oficio conocido, 37 eran labradores, 6 pescadores, 2 vaqueros, 2 mozos y 1 pastor; los artesanos incluían 17 del sector textil, 6 del cuero y calzado, 7 de otros ramos, y se añaden 2 mesoneros, 1 molinero y 3 sayones; los profesionales urbanos eran 3 mercaderes y 1 cirujano, y, finalmente, había 1 eclesiástico. 
que no llegaban al $3 \%$ de los acusados por este motivo, mientras representaban un $7 \%$ de los fuegos de la villa. Si una de las claves del recurso a la violencia era la desconfianza ante la capacidad de las instituciones judiciales para resolver los conflictos, puede pensarse que estos sectores burgueses manifestaban una actitud más «cívica» que sus convecinos. Ahora bien, su confianza en la justicia sin duda se veía estimulada por otros factores, como el hecho de que su predominio socioeconómico como terratenientes, mercaderes o profesionales cualificados se completaba con el control de la justicia local, que se hallaba sobre todo en manos de mercaderes y notarios. La villa era una «república de labradores», pero los cargos municipales y judiciales de mayor relevancia estaban prácticamente monopolizados por esta «burguesía» local ${ }^{47}$. Ahora bien, esto no significaba que el resto de agresores no hubiese tenido acceso a cargos políticos de la villa. Por el contrario, un $30 \%$ de los atacantes eran prohombres que ya habían ocupado —o accederían posteriormente- el oficio de consejero municipal. Esta proporción era equivalente a la de vecinos en general que habían participado en el gobierno de la villa ${ }^{48}$, de manera que se confirma que el perfil social de los agresores coincidía con el del conjunto de la sociedad local. No eran elementos marginales, sino vecinos respetables de la propia comunidad.

A pesar de que los atacantes se reclutaban sobre todo entre los campesinos y los artesanos, no pertenecían necesariamente a las capas de menor riqueza. La dificultad de establecer el nivel económico de los protagonistas reside en el escaso número de padrones de riqueza (llibres de la peita) conservados, de manera que no siempre se conoce el patrimonio del implicado en el mismo momento en que tuvo lugar el incidente violento. Sin embargo, estos datos se pueden completar si se considera que los vecinos que fueron consejeros debían poseer un patrimonio mínimo valorado en 2.000 sueldos $^{49}$. De esta manera, puede estimarse el nivel de riqueza de un total de 98 agresores, es decir, de un $64 \%$ del total ${ }^{50}$. Con esta información, a pesar de las distorsiones, se puede realizar una aproximación al nivel económico de los protagonistas de los hechos violentos. Así, queda claro que los vecinos más pobres — con patrimonios inferiores a

47 De un total de 109 mandatos anuales del cargo de justicia documentados entre 1375 y 1500 , el $58,7 \%$ fueron ejercidos por burgueses y el $14,6 \%$ por nobles, mientras que a los labradores sólo les correspondió el 20,1\% y a los artesanos un escaso 3,6 \%, cf. Viciano, Pau, Poder municipal..., op. cit., v. I, pág. 220.

${ }^{48}$ Ibidem, v. I, pág. 141.

49 Para la normativa de elección de los cargos y la riqueza de los prohombres de la villa, ibidem, págs. 62-132 y 256-312.

${ }^{50}$ De los 98 casos documentados, $11(11,22 \%)$ tenían menos de 1.000 sueldos de patrimonio, $26(26,53 \%)$ se situaban entre los 1.000 y los 1.999 sueldos, y $61(62,24 \%)$ igualaba o superaba los 2.000 sueldos. Hay que decir que los 55 agresores no identificados en los libros de la pecha no pueden considerarse como no contribuyentes - y que por tanto tendrían que situarse en el nivel inferior de riqueza-, ya que esta falta de datos debe relacionarse sobre todo con las lagunas documentales: desde 1398 a 1462 no se ha conservado ningún padrón de riqueza completo, y los de la segunda mitad del siglo son bastante espaciados. 
los 1.000 sueldos - sólo suponían una décima parte de los agresores, cuando eran más del $30 \%$ de la población local ${ }^{51}$. Ello no significa que no existiesen casos concretos de vecinos modestos caracterizados por la reincidencia en la violencia, y de hecho Macià Guerola, un herrero que en 1468 sólo disponía de un patrimonio tasado en 400 sueldos, había sido multado en tres ocasiones en 1467 , por dos peleas sin armas y por esgrimir un cuchillo en otro enfrentamiento ${ }^{52}$. Con todo, la nota dominante era que los vecinos más desfavorecidos de la comunidad local tendían a abstenerse de provocar incidentes violentos.

El sector intermedio-bajo — con patrimonios entre 1.000 y 2.000 sueldos- no parece haber sido especialmente violento, ya que presenta la misma proporción de atacantes - en torno a un $25 \%$ - que de contribuyentes en la pecha (peita). En este nivel de riqueza, sin embargo, se hallaban dos vecinos que habían sido multados en más de una ocasión: el labrador Jaume Miquel fue sancionado en 1467 por una pelea sin armas y, el mismo año, se presentó con sus hermanos Guillem y Francesc, «mà armada, a combatre la casa» de Pere Segarra, también campesino. A su vez, en 1495, los labradores Rafael Ferriols y Pere Molner hirieron a otro vecino, y, de joven, este último había herido, en compañía de su hermano Joan, al hijo de Pere Coma «en lo cap, del dit colp stava porillós e.n poder de metge» 53 .

En cambio, eran los vecinos de nivel medio o acomodado - con 2.000 sueldos o más de patrimonio- los que agredían con mayor frecuencia, dado que suponían entre un 40 y un $50 \%$ de la población, pero eran más del $60 \%$ a la hora de atacar a sus vecinos. Dentro de este amplio sector - conviene matizarlo- se daban comportamientos diferenciados. Los más violentos eran los vecinos de nivel medio-alto, que poseían patrimonios valorados en 2.000-3.999 sueldos, o que habían sido consejeros sólo de forma esporádica, puesto que representaban un $25 \%$ de la población pero habían protagonizado un $50 \%$ de los ataques. En cambio, la minoría de mayor nivel económico - con patrimonios iguales o superiores a 4.000 sueldos - y que monopolizaba los oficios de jurado y justicia no participaba en los incidentes violentos en mayor proporción que su escasa presencia demográfica (un $15 \%)^{54}$.

Los ataques de los vecinos que habían gestionado el poder local no parecen haberse dirigido preferentemente hacia sus colegas. De 23 víctimas conocidas de prohombres, quienes pertenecían al grupo político local eran un $30 \%$ de los

${ }^{51}$ Sobre la distribución de los vecinos en grupos de riqueza, a partir de los padrones de la pecha (llibres de vàlues de la peita) del AMC, cf. VICIANO, Pau, Poder municipal..., op. cit., v. I, pág. 44. El grupo inferior a 2.000 sueldos se distribuía así: hasta 999 sueldos eran el 27,6 \% en 1462, el 31,4\% en 1468 , el $29,7 \%$ en 1479 y el $34,5 \%$ en 1497 , mientras que los contribuyentes situados entre 1.000 y 1.999 sueldos eran el $25,8 \%$, el $28,8 \%$, el $26,9 \%$ y el $23,6 \%$, respectivamente. Los que tenían un patrimonio de 2.000 sueldos o superior eran el $46,52 \%$, el 39,74, el 43,2\% y el 41,77\%.

52 AMC, CJ, 18 de septiembre de 1467.

53 ARV, 6.949 y AMC, CJ, 17 de agosto de 1467, 20 de marzo de 1483 y 21 de enero de 1495.

${ }^{54}$ Los 61 agresores con un patrimonio igual o superior a 2.000 sueldos se dividían así: 48 con 2.000-3.999 sueldos (48,97\%) y 13 con 4.000 sueldos o más $(13,26 \%)$. 
afectados, que es la misma proporción que ocupaban en el conjunto de la población de la villa. Las diferencias de actitud han de buscarse en los atacantes que no habían pasado del nivel de consejeros. Los miembros de este estrato inferior de la «sociedad política» no acometían a los que ocupaban la cima de la jerarquía, sino a sus iguales y, sobre todo, a los vecinos excluidos del poder municipal, y entre éstos eran frecuentes las agresiones contra trabajadores jóvenes y subalternos como eran los criados (mossos). Así, en 1467 los labradores Pasqual Cerdà y Pere Barbarrossa, que serían consejeros en la década de los setenta, tuvieron una pelea porque éste se desdijo de una compra de trigo que había apalabrado con el primero ${ }^{55}$. Más grave aún fue la acción del pelaire Joan Peris - y no obstante entraría años después en el consejo de la villa- cuando en octubre de 1456, según la denuncia de Guillem Capcir, un tendero que pocos meses antes todavía ejercía como consejero, había ido a la plaza mayor, «acordadament e mà armada, ab armes per matar-lo, e li tirà una gran coltellada e si no com se retragué l'aguera dapnificat ${ }^{56}$. Y entre los prohombres violentos que atacaron a vecinos desvinculados del poder municipal, puede destacarse, en junio de 1441, la incursión de los labradores Bartomeu Bonet y del joven hijo de su hermano Pere - los dos hermanos consejeros en el ejercicio anteriorcontra Berenguer Gatell, que se hallaba trabajando en su campo, «per a matarlo». Pero la agresión más violenta fue la muerte en 1448 de un esclavo de Llorenç Miquel a manos de Arnau Merí, que había sido consejero dos años antes ${ }^{57}$.

\section{UNAS VÍCTIMAS DÉBILES}

En general, las víctimas de la violencia pertenecían a un medio social semejante al de los agresores, aunque se ha de subrayar que había una mayor presencia de mujeres, criados agrícolas y de algún personaje marginal entre los que recibían los golpes o las cuchilladas. En efecto, las mujeres que agredieron a otras personas no llegaban al $3 \%$ de los atacantes, mientras las víctimas femeninas ascendían a un $10 \%$ del total. Normalmente se trataba de peleas entre mujeres, como la que provocó en 1485 la esposa de Pere Granyana contra na Joana o las heridas que en 1454 causó la mujer de en Far a Caterina, la esposa de Pere Teixidor ${ }^{58}$. Los niños y jóvenes, también podían recibir alguna bofetada de mujeres como na Barbarrossa ${ }^{59}$, e incluso algunas habían intentado

${ }^{55}$ Pere Barbarrossa afirmaba que «aquell bo d'en Pasqual Cerdà, que $m$ havia comprat dos cafiços de forment, e ara met-se en com no.ls vol prendre. Tant me dóna que.ls prenga com que no", AMC, CJ, 8 de agosto de 1467.

56 AMC, CJ, 22 de octubre de 1456.

57 AMC, CJ, 26 de junio de 1441 y 17 de octubre de 1448.

58 AMC, CJ, 26 de enero de 1485 y 20 de agosto de 1454, donde Caterina Teixidor denunciaba que la agresora «la havia batuda e li havia tirades dues pedres e nafrada a ella».

59 AMC, CJ, 29 de agosto de 1442, Bartomeu Penyarroja denunció a na Barbarrossa porque «donà e o havia donat bun buffet a son fill». 
golpear a hombres con armas improvisadas durante el transcurso de una discusión. Fue el caso, en 1442, de la mujer de Salvador Amiguet, que ante la multa que le exigía el sayón Pere Sardo, «la muller del dit en Salvador li bavia tolta la penyora e li havia volgut dar ab lo legó al cap» ${ }^{60}$. En conjunto, sin embargo, ejercer la violencia - y más la armada - era cosa de hombres, hasta el punto de que la proporción de agresoras ni siquiera era comparable a la presencia pública de las vecinas - en torno al $10 \%$ - que contribuían como cabezas de familia en la pecha.

Las agredidas eran sobre todo víctimas de los hombres y, en primer lugar, de sus propios parientes. En 1441, los malos tratos que Jaume Gatell infligía a su mujer, hasta el punto de herirla, fueron denunciados por su suegro, y ya en 1467, Ursula, hija de Francesc Agramunt, consiguió separarse de su violento marido, el pelaire Miquel Castell, después de que éste, afectado por una enfermedad mental, le "havia trencat lo braç e aprés ab lo coltell arrancat li havia fet un bony al cap". En 1419 la mujer de Bartomeu Palacià fue agredida a golpes de caña por Antoni Ferriols, su propio tío ${ }^{61}$. Fuera del ámbito familiar, la violencia tampoco era extraña: un prohombre importante como Jaume Cerdà no dudaba en apalear a su joven criada; la anciana Sibília Valentí es insultada y golpeada con el asta de una lanza por Miquel Cireró, y la mujer de Bernat Esparça, estando a la puerta de su casa, recibió en 1495 un botellazo de Joan Navarro ${ }^{62}$. Los testimonios, ciertamente, son fragmentarios, pero aquí y allá presentan a las mujeres de la villa como vulnerables a los ataques de los vecinos, siempre sin que se haga un uso letal de las armas, y quizá más por humillar e insultar que con ánimo de causar heridas graves. El peligro parece venir más de la propia familia, sobre todo de los maridos y, para las adolescentes y jóvenes, de aquellos «padres crueles» que son los amos de la casa donde sirven como criadas. El pater familias veía reconocido su derecho a corregir con la violencia las faltas de la esposa y la holgazanería o insubordinación de los criados que tenía a su servicio. En todo caso, lo que podía considerarse una trasgresión era el exceso de brutalidad: Úrsula Agramunt subraya ante el justicia que los malos tratos de su marido se habían producido sin haberle dado motivos — «sens causa d'ella»—, mientras que las críticas contra Jaume Cerdà no cuestionan que la moza tenga que ser golpeada de vez en cuando, sino que corregir a la joven no correspondía al amo sino a su mujer ${ }^{63}$.

El recurso a la violencia por parte de los maridos era un hecho cotidiano, y para tratar de frenar los excesos más escandalosos, las mujeres y sus familias

${ }^{60}$ AMC, CJ, 18 de agosto de 1442.

${ }^{61}$ AMC, CJ, 20 de mayo de 1441 y 28 de noviembre de 1467; ARV, MR, 6.942.

62 AMC, CJ, 22 de agosto de 1467, 18 de marzo de 1441 y 10 de junio de 1495, donde el marido de la agredida afirmaba que «és vengut lo dit Johan Navarro ab una ampolla de vidre plena de grans inmundícies, estant una tassa e miga, poch más o meys, e tirà-lli a la cara la dita ampolla por injuriar e greument naufregar la dita dona».

${ }^{63}$ Iolant, la mujer de Bernat Coll, recriminó al amo que «no's conexia de batre axí la fadrina, car lo batre de la fadrina devia fer sa muller, e que ell no li devia dar tant desmoderament", AMC, CJ, 22 de agosto de 1467. 
podían conseguir del esposo el compromiso jurídico, ante el justicia, de no maltratarla desmesuradamente. En estos acuerdos, como el que suscribió en 1466 el labrador Pere Marco para «asegurar» a su mujer, Úrsula, el marido prometía a la esposa que «no la maltractarà desordenadament e talment que la persona de aquella vingués a morir e de mort» ${ }^{64}$. Pero las mujeres, sobre todo las jóvenes, se hallaban expuestas a otro tipo de violencias, como eran las agresiones sexuales ${ }^{65}$. A finales de marzo de 1466 fue encarcelado el joven Guillem Gomar, acusado de haber intentado violar a una criada de Bartomeu Penyarroja y a una hija de Nicolau Miró, las dos de corta edad ${ }^{66}$. Según la propia confesión de Guillem Gomar, mientras buscaba una yegua que había huido del rebaño que cuidaba, encontró en un lugar solitario de la partida de Coscollosa a la moza de en Penyarroja, y tras intercambiar algunas palabras, intentó cometer la agresión que, según el acusado, no fue consumada a causa de la resistencia de la víctima. Tampoco reconocía haber forzado a la hija de Nicolau Miró, aunque confesó que le propuso mantener relaciones sexuales y se abalanzó sobre ella, cuando ambos coincidieron en la partida de Rafalafena, él cuidando de una yeguada y la joven de una piara ${ }^{67}$. Más brutal fue la violación colectiva de una prostituta anónima —una mujer «pública e mundària»— perpetrada por un grupo de habitantes de la villa en $1491^{68}$. Según denunciaba la víctima, los agresores eran cinco jóvenes, a los que se acusaba de haber abusado de la mujer con engaños y de haberla golpeado e injuriado: "haver presa la dita dona e, fraudulentament e enganosa, haver-la portada en huns corrals de la dita vila, ab la qual carnalment usaren ab aquella contra llur [sic] voluntat, e encara la tractaren mal de bufets e altres injúries» ${ }^{69}$. Estos agresores no pertenecían a los ambientes marginales.

${ }^{64}$ AMC, CJ, 2 de enero de 1466. Hay que decir que siete meses después, el 11 de agosto, los cónyuges aprobaron un nuevo compromiso, pero ahora con carácter recíproco. De un total de 46 de estos acuerdos recogidos entre 1438 y 1495, sólo 7 (un $15 \%$ ) hacían referencia a conflictos conyugales.

${ }_{65}$ Para el caso castellano existen estudios como los de Cóndoba DE LA Llave, Ricardo: El instinto diabólico. Agresiones sexuales en la Castilla medieval, Córdoba, 1994; PALlarés, M. ${ }^{a}$ Carmen: «Conciencia y resistencia: la denuncia de la agresión masculina en la Galicia del siglo XV», Arenal, 2 (1995), págs. 67-79, y BAZÁN, Iñaki: «El estupro. Sexualidad delictiva en la Baja Edad Media y primera Edad Moderna», Mélanges de la Casa de Velázquez, 33 (2003), págs. 13-46.

${ }^{66}$ AMC, CJ, 28 de marzo de 1466. Guillem Gomar declaró ante el justicia que, al encontrarse con la víctima, le vino «voluntat de fer-lo·y, pres aquella e lançà-la en terra e alçà-li les faldes, e per ço que la dita moceta no'u volia, dient-li que la dexàs (...) e que no li fes res, e que lavors diu que passà-li aquella voluntat e jaquí-la's allí e anà-se'n a cercar la egua».

${ }^{67}$ Ibidem. Según la confesión realizada ante el justicia, «stava en veritat que deçà Nadal, stant en la partida de Rafalafena guardant les egües e la filla d'en Nicholau Miró los porchs, lo dit Guillem Gomar demanà que li prestàs lo cony, e que la dita fadrina li dix que no'u volia fer, que si passava algú ho veurien, e que ell, tenint voluntat de fer-lo·y, abraçà-la e lançà-la en terra, e ell damunt, sens alçar-li les faldes, e que ella dient-li: "Lleva't d'aquí, no vull que'm faces res", que si u vehia algú, dirien-ho a son pare d'ella e oncle d'ell, e que axí, sens fer-li pus res, se'n anà ab les egües».

68 AMC, CJ, 9 de marzo de 1491.

${ }_{69}$ Este tipo de agresión tiene una gran semejanza con los ataques de bandas juveniles que 
Entre ellos, se puede identificar a dos herreros - Jaume Eiximeno y Joan Albesa - y un labrador — Pere Segarra—, todos de edad más bien joven ${ }^{70}$. Por otra parte, tres de ellos eran miembros de familias que participaban en el poder municipal ${ }^{71}$. En concreto, el padre de Jaume Eiximeno, también herrero, era un prohombre destacado de la villa tanto por el valor de su patrimonio, como por su presencia en el gobierno municipal, del cual sería consejero precisamente en 1491-149272. Una vez más, los hechos violentos no podían imputarse al mundo de la marginación sino a sectores integrados de la villa y, en este caso, incluso vinculados al grupo que accedía al poder municipal.

Como las mujeres, los sectores más débiles de la comunidad local figuran en la documentación del justicia más a menudo como víctimas que como agresores. Los criados — básicamente mozos agrícolas—, sobre todo hijos de los campesinos pobres, unían a su condición de trabajadores asalariados la dependencia de la autoridad del amo, a la vez patrón y padre de la familia donde, de manera subalterna, se veía integrado el joven ${ }^{73}$. Si los mozos de labradores, unidos a algún aprendiz de artesano, sólo representaban un $1 \%$ del grupo violento, eran casi el $13 \%$ de las víctimas, a veces maltratados por adultos y con frecuencia por otros jóvenes de la villa. Y también resulta significativo que no figure ningún marginado entre los agresores, cuando los pocos que se vieron implicados en violencias - un pobre, un esclavo que terminó muerto, un sarraceno y una prostituta - lo fueron como agredidos. En cambio, la presencia de jóvenes pendencieros —identificados como hijo (fill o fadrî) de un vecino adulto, que es quien paga la multa - es equivalente en los dos lados: alrededor del

sufrían las mujeres de las ciudades de Borgoña En Dijon los jóvenes violadores no se reclutaban entre los sectores marginales y de inmigrantes recientes, sino entre los artesanos integrados en la ciudad y otros grupos sociales enraizados en la sociedad local, según Rossiaud, Jacques, La prostitución en el medievo, Barcelona, 1986, págs. 23-34.

${ }^{70}$ Jaume Eiximeno, el hijo, y Joan Albesa eran herreros, mientras que Pere Segarra es identificado en diversos lugares como labrador. Sólo dos de los agresores — Joan Miquel y Jaume Eiximeno- figurarían en el padrón de la peita de 1497 como contribuyentes adultos, pero con unos patrimonios aún reducidos, mientras que no parece Pere Valero.

${ }^{71}$ Un Pere Segarra había sido consejero en 1459-1460, 1462-1463 y 1464-1465, y un Pere Valero, aparte de haber ejercido también como consejero en esa época, fue almotacén en 14611462, cf. AMC, LC.

${ }^{72}$ Jaume Eiximeno, el mayor, fue jurado en 1493-1494 y 1497-1498, además de ejercer al menos 13 mandatos como consejero municipal desde 1471-1472 a 1500-1501, cf. AMC, LC. Buena prueba de esta posición dominante en el seno de la comunidad local és que en 1497 poseía un patrimonio valorado en casi 6.000 sueldos, una suma tres veces superior a la media, cf. AMC, Llibre de Válues de la Peita (1497). Sobre la resolución del caso, que supuso la práctica absolución de los acusados, vid. VICIANO, Pau: «El bordell dels prohoms. El control municipal de la prostitució al Castelló del segle XV», Anuario de Estudios Medievales, 51/1 (2005), págs. 327-358..

73 Por lo que respecta a la condición social de los mozos agrícolas y su función económica, vid. Furió, Antoni, Mira, Antonio J. y Viciano, Pau: «L'entrada en la vida dels joves en el món rural valencià a finals de l'Edat Mitjana», Revista d'Història Medieval, 5 (1994), pp. 75-106, en el dossier «Fer-se grans. Els joves i el seu futur al món medieval», coordinado por Enric Guinot. 
$15 \%$ de los agresores y de las víctimas, unas categorías éstas que, en el caso de las peleas espontáneas quedan desdibujadas. El azar o la rapidez con que uno de los jóvenes esgrimía el cuchillo era normalmente el único criterio que permitía a las autoridades diferenciar entre agresor y agredido. A pesar de este margen de ambigüedad, no deja de ser significativa la diferencia global entre el nivel socioeconómico de los atacantes y el de las víctimas de la violencia.

De un total de 104 víctimas identificadas, más de la mitad — si consideramos a las de oficio desconocido como campesinos - eran labradores, una proporción bastante inferior a la que este sector mayoritario representaba como agresores y en el conjunto de la población de la villa. Los artesanos no destacaban como objeto de los ataques, puesto que su presencia como víctimas — poco más del $20 \%$ - era similar a la que tenían como agresores y como vecinos del conjunto de la comunidad. Los burgueses —especialmente mercaderes-, a su vez, eran con mayor frecuencia objeto de la violencia que agresores, si bien su porcentaje en el total de víctimas no superaba su relieve demográfico. La mayor distorsión entre el nivel socio-profesional de los agresores y de las víctimas se hallaba sobre todo en el sector de los labradores y en el de la población subalterna, compuesta por algunos marginados y, especialmente, por mozos o criados agrícolas. En este sentido, los labradores eran con mayor frecuencia agresores que víctimas, mientras que el sector subalterno era prácticamente inexistente entre los atacantes, pero representaba un $15 \%$ de las víctimas. De hecho, los mozos eran diez veces más numerosos como víctimas que como agresores, mientras que los marginados aparecían sólo como objeto de la violencia, incluyendo uno de los dos homicidios documentados.

Globalmente, el nivel de riqueza predominante entre los agredidos debía de situarse por debajo del que tenían los vecinos violentos. Un $17 \%$ de las víctimas - mozos y marginados - se hallaban entre los habitantes más pobres de la villa, con toda seguridad con menos de 1.000 de sueldos de patrimonio, si es que tenían alguno. Probablemente esta proporción sólo representaría un mínimo, ya que otros vecinos - especialmente entre los campesinos y los artesanos - también se situarían en este estrato inferior, que entre los agresores, en cambio, estaba en torno al $10 \%$. Este menor nivel de riqueza de las víctimas respecto al conjunto de agresores se confirma si se tiene en cuenta que de un centenar de vecinos damnificados, sólo habían participado en el poder local, y por tanto les correspondería el nivel de riqueza superior a la media, un $23 \%$ del total, cuando entre los atacantes los prohombres llegaban a ser el $30 \%$.

Las agresiones cotidianas, tal como se documentan en las denuncias y en las multas, en general eran protagonizadas por individuos aislados, más que por bandas organizadas. De hecho, de 145 incidentes violentos en que consta la identidad del atacante, sólo en uno de cada diez se detecta la presencia de diversos agresores. Los vínculos que unían al grupo que cometía las violencias eran en parte familiares. Normalmente se trataba de hermanos, como era el caso de los jóvenes Joan y Pere Molner, pero también se daba la colaboración 
entre dos generaciones y, así, Bartomeu Bonet llevó a término su agresión en compañía de un sobrino, el hijo del su hermano Pere Bonet ${ }^{74}$. En una proporción más importante, estas asociaciones agrupaban a hombres de apellidos diferentes, que quizá fuesen cuñados o suegro y yerno, pero a falta de datos sobre las alianzas matrimoniales, hay que pensar que la vecindad y otras solidaridades extra-familiares tendrían un peso destacado en la cohesión de los atacantes. Las peleas o los atentados protagonizados por grupos de parientes o vecinos normalmente eran la expresión más crispada de unas tensiones que dividían el tejido social de la comunidad local. Un caso evidente fue el ataque que, en 1467, perpetraron los hermanos Jaume, Guillem y Francesc Miquel contra Pere Segarra. Que no se trataba de un hecho aislado, de una simple pelea espontánea, quedaba claro en la propia denuncia, pero la verdadera dimensión del enfrentamiento se hace más patente si se tiene en cuenta que el justicia forzó a las partes a firmar una paz que vinculaba a los respectivos «parents, amics e valedors $\gg^{75}$. Es decir, el estallido violento sólo era un episodio de la lucha entre el bando de los Miquel y el de los Segarra.

\section{LA VIOLENCIA SOLIDARIA}

La violencia organizada no era patrimonio exclusivo de la aristocracia ni de los gremios urbanos ${ }^{76}$, sino que el mundo rural, desde las villas más importantes hasta las pequeñas comunidades campesinas, también veía amenazada su estabilidad por las luchas de bandos ${ }^{77}$. De hecho, en una comunidad semiurbana como Castellón, había vecinos de todos los niveles sociales involucrados en los bandos. A partir de 208 paus $i$ treves que se firmaron por los bandos enfrentados ante el justicia, entre 1439 y $1495^{78}$, se han identificado a 426 personas, prácticamente todos vecinos de la villa, que con plena seguridad se vieron implicados en las luchas de facciones. A título indicativo, ello representaría una media de 26 personas por año, es decir, que uno de cada treinta vecinos al ini-

74 AMC, CJ, 20 de marzo de 1483 y 26 de junio de 1441, respectivamente.

75 AMC, CJ, 17 de agosto de 1467.

76 Los bandos protagonizados por nobles y artesanos en la ciudad de Valencia han sido estudiadas por NARBONA, Rafael, Malhechores..., op. cit., y, del mismo autor, «Violencias feudales en la ciudad de Valencia», Revista d'Història Medieval, 1 (1990), págs. 59-86.

77 Para las zonas rurales valencianas, pueden citarse la aproximación de FURIÓ, Antoni, y GARCIA-Oliver, Ferran: «Del dia i la nit...», art. cit., págs. 46-47 y la síntesis general de FuRIÓ, Antoni, «Las comunitats rurals de l'Horta-Sud de l'Edat Mitjana als temps moderns», Afers, 11/12 (1991), págs. 31-55; un estudio monográfico más centrado en el tema de la solidaridad y el conflicto es el de VERCHER, Salvador: Casa, família i comunitat veïnal a l'borta de València. Catarroja durant el regnat de Ferran el Catòlic (1479-1516), Catarroja, 1992, págs. 113-117.

${ }^{78}$ Las 208 paces se recogen en 16 libros de la corte del justicia de la siguiente manera: AMC, CJ, 1439 (8 paces), 1441 (12), 1442 (3), 1447 (9), 1454 (10), 1455 (10), 1456 (12), 1465 (5), 1466 (17), 1467 (29), 1480 (13), 1483 (10), 1485 (4), 1491 (10), 1492 (5) y 1495 (37). 
cio del período o uno de cada veinte al final, habrían tomado parte en los bandos $^{79}$. La negociación de la paz entre los contendientes, cuando a menudo se había pasado al derramamiento de sangre, no era una labor fácil para las autoridades. En efecto, las agresiones armadas cometidas «acordadament» —con premeditación - solían ser una vendetta más dentro de un conflicto de bandos de mayor alcance. Este era el caso del ataque, cuchillo en mano, de Joan Peris contra Guillem Capcir en 1456, y del atentado que en 1467 intentaron los hermanos Miquel contra Pere Segarra. El deseo de venganza podía impulsar al bando que se consideraba agraviado a preparar incluso una emboscada en un camino solitario para matar al contrincante. Así, en 1441 Pere de l'Espasa pudo librarse de este grave peligro gracias al aviso de un vecino de buena voluntad, que prefirió no divulgar la identidad de los posibles agresores, aunque reconocía que todo provenía «de lo fet dels Marquesos» ${ }^{80}$. Normalmente, el municipio designaba a unos mediadores neutrales que se encargaban de tratar las condiciones con las partes enfrentadas. En 1453, el consejo municipal nombraba a dos prestigiosos prohombres para conseguir que se reconciliasen los Granyana y los $\mathrm{Marco}^{81}$, pero no era sorprendente que estallase la violencia arruinando las gestiones pacificadoras, como sucedió en 1467 entre el bando de Macià Guerola y el d'Antoni Balaguer, que reabrieron las hostilidades ante la impotencia de los mediadores, Jaume Miquel y Bernat Pelegrí ${ }^{82}$.

Los documentos de pau e treva ${ }^{83}$, en que las partes se comprometían a cesar las hostilidades, permiten conocer la identidad de las personas que integraban los bandos y, en menor medida, los vínculos de solidaridad que las aglutinaban. Sin embargo, en la mayoría de los casos —alrededor de un $75 \%$ - sólo se mencionaba a los dirigentes de la facción, sin que se mencionen explícitamente a sus «parents, amics e valedors». En el resto de los documentos parecen predominar los lazos corporativos o de vecindad sobre el parentesco, que suele reducirse a padres e hijos o hermanos. Es posible, no obstante, que el vínculo familiar permanezca sumergido entre los compañeros de diferente apellido, ya que podría tratarse de familiares afines, básicamente cuñados o suegros y yernos, como era el caso del enfrentamiento citado entre los Capcirs y Pere Mut. Un

79 La población de la villa, según los registros fiscales del monedaje (morabatî), tenía 694 fuegos en 1439 y disminuyó a 479 en 1493, vid. la síntesis de GuINOT, Enric, «Demografia medieval...», art. cit.

${ }^{80} \mathrm{El}$ aviso lo hacía Francesc Maimó con estas palabras: «yo venint de Nul·les e trobat aquí prop lo moló de Nul-les quatre hòmens, los quals han dit que vós devíeu pasar anit o buy, que huy vos speren e que han jurat a Déu que si vós passau que no plegareu a València», AMC, CJ, 2 de enero de 1441.

81 AMC, LC (1453-54), 22 de agosto de 1453.

82 AMC, CJ, 8 de septiembre de 1467.

${ }^{83}$ Un ejemplo del formulario puede ser la siguiente paz: «Bernat Rochamartí e Bernat Reboll, vehins de la vila de Castelló, de una part, e Domingo Gaçó, Pere Gaçó d'Almassora e Johan Gaçó, de la part altra, feren e fermaren pau final e treva duradora a CI anys sobre qualsevol qüestions, bregues e prometeren no fer-se mal ni dan en alcuna manera, pena bària e trayció e pena C florins», AMC, CJ, 26 de junio de 1439. 
buen ejemplo de la amplitud que podían alcanzar las redes de parentesco a la hora de constituir los bandos es el conflicto, abierto en 1466, de Joan Vilarroig y su hijo, del mismo nombre, contra el «clan» de los Martí, que incluía a los tres hermanos Miquel, Joan y Pere, y a los jóvenes hijos de este último, llamados Joan, Pere y Guillem ${ }^{84}$. Y aunque los lazos familiares solían ser de solidaridad, también había algún caso en que la violencia surgía en el interior de un mismo grupo de parientes. Esto ocurría en 1441, cuando Berenguer Miró y sus hijos Pasqual y Joan se enfrentaron a su pariente Pasqual Miró ${ }^{85}$.

A pesar de la dimensión política de algunos enfrentamientos, los integrantes de los bandos que participaban —o habían participado en alguna ocasiónen el gobierno de la villa no llegaban a un tercio del total, una proporción semejante a la de vecinos en general que ocuparon cargos municipales. La mayoría de los «bandoleros», pues, estaban excluidos del poder político local, aunque a veces pudiesen verse arrastrados por las facciones de prohombres. El oficio de estos vecinos dispuestos a practicar una violencia de grupo confirma la diversidad de su extracción socio-profesional, que reproducía a grandes rasgos la del conjunto de la población. De los 426 miembros de los bandos identificados, los labradores representaban una cuarta parte, pero si se considera que la inmensa mayoría de los de oficio desconocido también debían de ser campesinos, este sector representaría casi un $60 \%$ del total, un peso equivalente al que tenían en la sociedad local. Los artesanos, en cambio, se hallaban sobrerrepresentados en los bandos, ya que eran un $30 \%$, cuando sólo llegaban al $20 \%$ de la población de la villa. Los burgueses, con un $8 \%$, tenían la misma presencia en las facciones que en el conjunto de la sociedad local, mientras que su relevancia como agresores a título individual — como hemos visto - era mucho más reducida, inferior al $3 \%$. Además, en esta forma de violencia colectiva participaban incluso notarios y estudiantes, que no constan en las multas y denuncias por agresiones aisladas. Y también es significativo que la única ocasión en que se acusó a un noble local de hechos violentos - el doncel Garcia de Sayes - fuese en el marco de las luchas de bandos ${ }^{86}$. Los bandos, pues, eran la forma de comportamiento violento más característica de los grupos de nivel profesional - y económico- elevado, en comparación con su participación en las otras modalidades de agresiones. Sin embargo — conviene subrayarlo-, en una visión de conjunto, la distribución por oficios de los miembros de las facciones, donde predominarían los labradores, venía a coincidir, con pocas distorsiones, con la estructura socio-profesional de la villa: los bandos estaban integrados por gente común.

${ }^{84}$ AMC, CJ, 24 de enero de 1466.

${ }^{85}$ AMC, CJ, 20 de febrero de 1441. Un caso semejante de bandos intrafamiliares era el conflicto de los hermanos Vicent y Jaume Tarassona, según la paz del 10 de febrero de 1455 .

${ }^{86}$ Ahora bien, no se trataba de ningún episodio caballeresco, ya que los adversarios eran los pelaires Berenguer Castell y Joan de la Foz, y el labrador Rafael Ferriols, AMC, CJ, 21 de noviembre de 1495 . 
CUADRO 2: NiVEL SOCIO-PROFESIONAL DE LOS MIEMBROS DE LOS BANDOS

\begin{tabular}{lrr} 
NIVEL SOCIO-PROFESIONAL & NÚMERO & $\%$ \\
\cline { 3 - 4 } labradores & 100 & 23,47 \\
artesanos & 127 & 29,81 \\
burgueses & 34 & 7,90 \\
nobles & 1 & 0,23 \\
eclesiásticos & 5 & 1,17 \\
subalternos & 6 & 1,40 \\
minorías & 6 & 1,40 \\
desconocido & 148 & 34,74 \\
\hline TOTAL & 426 &
\end{tabular}

La idea de que los bandos no tenían un componente elitista, sino que agrupaban a vecinos comunes aún se refuerza si, además de tener en cuenta la profesión y la relevancia política de sus miembros, se considera su nivel de riqueza. Tomando como muestra los 75 contribuyentes del padrón de 1468 que, en una fecha cercana, figuraron firmando alguna pau e treva, puede constatarse un predominio de los estratos medios de riqueza. En comparación con el conjunto de los contribuyentes de aquel registro fiscal, los vecinos que tendían a no participar en las facciones eran los de nivel inferior y superior: los que poseían menos de 1.000 sueldos de patrimonio eran más de un $30 \%$ de los contribuyentes, pero sólo un cuarto de los miembros de los bandos, mientras que en el caso de los que tenían 4.000 sueldos o más, la proporción de contribuyentes era de un $13 \%$, pero no llegaban al $10 \%$ como integrantes de las facciones. En cambio, los estratos medios - entre 1.000 y 4.000 sueldos de patrimonio- tendían a predominar en las luchas de facciones, donde suponían un $64 \%$ de sus miembros, aunque sólo eran un $55 \%$ del total de contribuyentes ${ }^{87}$.

La menor presencia de vecinos modestos en las facciones debe relacionarse con la mayor debilidad de sus redes sociales. Siendo una violencia basada en los lazos de solidaridad, los estratos más débiles de la sociedad local tenderían a quedar al margen de esta modalidad de enfrentamientos. Evidentemente, un bando encabezado por un notable local podía agrupar, a través de solidaridades verticales y lazos de patronazgo, a vecinos más modestos e incluso mozos y criados. En 1492 el mercader Nicolau Casalduc, un destacado prohombre, se enfrentaba a los pelaires Joan Martí y Martí Llopis, con la ayuda de su mozo

${ }^{87}$ Los 75 miembos de bandos que figuran en el padrón de riqueza de 1468 se repartían según los siguientes niveles: con 1-999 sueldos 20 (26,66 \%), con 1.000-1.999 sueldos 23 (30,66\%), con 2.000-3.999 sueldos 25 (33,33\%) y con 4.000 sueldos o más $7(9,33 \%)$. Para el conjunto de los contribuyentes registrados en el padrón, la distribución por dichos niveles de riqueza era, respectivamente, $31,44 \%, 28,80 \%, 26,45 \%$ y 13,29\%, AMC, Llibre de Vàlues de la Peita (1468). 
Ferrando Guerau ${ }^{88}$. De esta manera, aunque los burgueses representaban una parte reducida del total de miembros de los bandos, su influencia como dirigentes de las facciones podía ser mucho mayor de lo que dejaría entrever su escasa relevancia cuantitativa. Incluso podían estar detrás de actos de violencia cometidos por sus partidarios. En 1455 Joan Belsa, un pescador acomodado que entonces era consejero municipal, fue herido por Pere Sanou de «dos colps en la cara», que acabaron provocándole la muerte. Según denunciaba su viuda ante el justicia, los instigadores de la agresión — «aquells qui han tengut mà e giny en les nafres»— eran los hermanos Francesc y Joan Miquel, unos poderosos mercaderes que también participaban habitualmente en el gobierno local ${ }^{89}$. Se daba el caso de que, según la denunciante, en aquel momento estaba vigente una paz y tregua firmada por la víctima y los Miquel, lo cual indica que se habían producido enfrentamientos entre las dos partes. Buena prueba de la influencia de estos mercaderes es que, a raíz de la denuncia, no fueron encerrados en la cárcel, sino simplemente arrestados en el palacio de la villa. El proceso se vio entorpecido por dilaciones inexplicables. El jurista Pere Miralles rechazó representar a la viuda, por no romper la tregua que tenía pactada con los Miquel y un año después no sólo se encontraba en libertad el homicida, sino que la documentación del proceso había desaparecido misteriosamente de la corte del justicia. Finalmente, los acusados continuaron su brillante carrera política, sin que estas graves acusaciones les hubiesen desprestigiado, e incluso Francesc Miquel ocuparía el oficio de justicia en 1460-146190. Ahora bien, a pesar de estos ejemplos, más bien excepcionales, de bandos jerarquizados y encabezados por prohombres poderosos, en la inmensa mayoría de las paces —un $75 \%$-, sólo consta el nombre de los dirigentes de cada bando, con una referencia genérica a sus «parents, amics e valedors». Todo hace pensar que estas facciones tenían una menor complejidad social que la de los bandos urbanos, y que solían estar dirigidas por vecinos comunes, a los cuales se unían un puñado de parientes o de amigos ${ }^{91}$.

Lo que sí que puede asegurarse es que al agrupar a los miembros de los bandos por apellidos, se hace patente que había una minoría de familias, en el sentido extenso, que aportaban más hombres a las luchas que el resto. La mayoría de estas familias amplias sólo participaba en los conflictos a través de uno

88 AMC, CJ, 9 de junio de 1492.

${ }^{89}$ Sobre esta familia de la oligarquía local, cf. ViCiANO, Pau, «La promoción social de una familia de mercaderes valencianos. Los Miquel de Casellón en el siglo XV», Hispania, 53 (1993), págs. 971-986.

90 AMC, CJ, 26 de abril y 5, 6, 9 y 13 de mayo de 1455, y 5 de agosto de 1456.

${ }_{91}$ Estos bandos, por tanto, no eran comparables, por citar un ejemplo característico, al caso de los banderizos vascos, al que se han dedicado obras recientes como Díaz DE DURANA, José Ramón (ed.): La lucha de bandos en el País Vasco: de los Parientes Mayores a la Hidalguía Universal, Bilbao, 1998, y DAcosta, Arsenio: Los linajes de Bizkaia en la Baja Edad Media. Poder, parentesco y conflicto, Bilbao, 2004. 
de sus miembros, pero 9 de ellas implicaron en diferentes bandos, durante el siglo XV, a 5 o más vecinos del mismo apellido ${ }^{92}$. Se trataba de los Martí, Miró, Feliu, Miquel, Castell y otros «linajes» que eran los más enraizados en la villa, tanto por su presencia ininterrumpida a lo largo de todo el siglo XV, como por su diversificación en numerosas familias conyugales ${ }^{93}$. Este vigor demográfico era característico de las familias dominantes y, de hecho, todas pertenecían al grupo que gestionaba el poder municipal. En definitiva, las facciones violentas se nutrían de todas las capas de la sociedad local, desde criados a prohombres del consejo, pero eran estas familias dominantes las que, a pesar de su reducido peso cuantitativo, podían desestabilizar la vida pública en su lucha por el poder.

Durante la primera mitad del siglo XV, cuando el sistema de elección de los cargos — cooptativo en la práctica - facilitaba a las oligarquías asentadas en el poder vetar —o al menos dificultar — la entrada en el consejo de otras facciones de prohombres, afloraban las tensiones entre las principales familias. Entonces el juego político podía continuar "por otros medios» en las calles y caminos de la villa. Esta situación aún se volvió más conflictiva a partir de los años veinte, en el contexto del inicio de una fuerte recesión demográfica y económica, que haría disminuir la población de la villa de un millar de fuegos en 1422 a sólo unos 650 en $1451^{94}$. Este declive demográfico iba unido a una reducción de la actividad económica y, por tanto, de la fiscalidad municipal, que se vio impotente para hacer frente a una deuda pública asfixiante ${ }^{95}$. Cómo se sanearía la hacienda local y quién tendría que pagar el costo de la crisis financiera, era una cuestión que se decidía en el consejo municipal, y ello favorecía el enfrentamiento entre las facciones. No es casualidad que en la década de los años veinte los bandos de la villa, sobre todo los protagonizados por los propios consejeros, llegasen a tal extremo de virulencia que se hizo necesaria la intervención pacificadora de la monarquía. Así, en 1425, Berenguer Castell, un poderoso mercader que ocupaba un lugar en el consejo, tuvo que aceptar una paz que cerraba la lucha que había sostenido contra su colega Pere de Reus,

92 Con un solo miembro había 141 apellidos, con 2 miembros 42, con 3 miembros 26, con 4 miembros 14 y con 5 o más miembros un total de 9 apellidos. En conjunto, hubo implicados en bandos 232 «linajes», que agrupaban un total de 426 personas.

93 Los apellidos Ferrer y Miquel tenían 5 miembros, Mas i Segarra 6, Castell y Miquel 7, Feliu 8, Miró 10 y Martí 13; a excepción de los Segarra, todos los demás figuran en los libros de la pecha de 1398, 1468 y en el censo de 1510, con el número de unidades conyugales más elevado, cf. de SÁNCHEZ ADELL, José: «Onomástica y movilidad de población en la villa de Castellón de la Plana (siglos XIV-XVI)», Saitabi, 28 (1978), págs. 33-68.

94 El estudio más reciente sobre la población de las comarcas castellonenses es el de GUINOT, Enric: «Demografia medieval...», art. cit.; por lo que respecta a los datos de 1422, AMC, LC (147879), 28 de septiembre de 1478.

95 Viciano, Pau: «Ingrès i despesa d'una vila valenciana del Quatrecents. Las finances municipals de Castelló de la Plana (1426-1427)», Boletín de la Sociedad Castellonense de Cultura, 66 (1990), págs. 635-664. 
con quien había coincidido en el anterior mandato. Con todo, durante este año continuaron los bandos entre los prohombres, y los jurados, incapaces de mitigar las violencias, decidieron recurrir a la autoridad de la corona ${ }^{96}$. Estas gestiones todavía continuaban en abril de 1427, cuando se envió a un mensajero al rey «per causa de las bandositats que eren en la dita vila» ${ }^{97}$. Dos años después, era la lucha entre los Capcir y Galceran de Reus contra Pere Mut y sus yernos, la que, según las autoridades locales, amenazaba a la villa con «scàndel e destruccions». Prueba de que las tensiones políticas no se resolvían sólo en las reuniones del palacio municipal, es que la mayoría de los implicados en estos bandos, incluyendo a los dirigentes, eran consejeros en activo aquel mismo año ${ }^{98}$. A pesar de la estrategia de presionar a los bandos para forzarlos a aceptar la paz, las amenazas de grandes enfrentamientos continuaron en 1430 y $1431^{99}$, lo que ponía de relieve la impotencia de las autoridades locales para resolver unos conflictos que, en buena parte, nacían del clima de desestabilización económica de la villa, y que tenían como protagonistas a prohombres del mismo medio social y político del que formaban parte los jurados. Finalmente, fue la persistencia de las luchas de bandos políticos la excusa que utilizó la monarquía para imponer, a pesar de la resistencia de los prohombres, una reforma municipal que sustituía la cooptación por la provisión de los cargos por sorteo -insaculación- en $1446^{100}$. Con todo, en una villa como Castellón, incluso los bandos políticos estaban lejos de tener la complejidad y la influencia de los partidos - fuertemente jerarquizados, cohesionados en torno a un nombre y una simbología propia ${ }^{101}$ _ que se disputaban el poder en las grandes ciudades me-

96 AMC, LC (1424-25), 3 de marzo y 26 de mayo de 1425.

97 AMC, Llibre de Rebudes i Dates (1426-27).

${ }_{98}$ El consejo forzó a las dos partes a suscribir una paz y tregua, donde se identificaban como miembros de un bando a Bonanat, Guillem i Domingo Capcir, este último consejero en activo, y por el otro lado estaban el labrador Pere Mut, también consejero, como sus yernos Pasqual Eiximeno, herrero, y Jaume Gascó, que más tarde sería justicia, mientras que otro de los yernos, el labrador Francesc Agramunt, había sido consejero dos años antes, AMC, LC (1429-30), 17 de julio de 1429.

99 AMC, LC (1429-30), 26 de febrero de 1430 y LC (1431-32), 26 de agosto de 1431.

${ }^{100}$ En el preámbulo del documento que establecía la insaculación se denunciaban «les distencions e discòrdies de los habitadors de aquelles [viles], les quals discòrdies principalment se demostren e exerciten en los officis e regiments de les dites ciutats e viles, per ço com cascú se treballa e esforça pe enantar e sublimar aquells ab qui té sa affecció e per desantar e derrerar als contraris», cf. la edición de ROCA TRAVER, Francisco A.: Ordenaciones municipales de Castellón de la Plana durante la Baja Edad Media, Valencia, Institución Alfonso el Magnánimo, 1952, p. 124. Los problemas, sin embargo, no acabaron con el cambio de sistema electoral, y en 1470 y 1471, según los libros de consells, volvieron a producirse graves bandos políticos.

101 Para una visión de la estructura y las actuaciones de los grandes partidos políticos es cláscia la obra de Heers, Jacques, Les partis et la vie politique dans l'Occident Médiéval, París, 1981. Sobre las solidaridades de los linajes patricios, puede verse la síntesis de MENJOT, Denis, «La clases dominant des villes de l'Occident méditerranéen au seuil de la Modernité», en 1490. En el umbral de la Modernidad, Valencia, 1994, págs. 181-203. 
diterráneas. Como mucho, se han documentado bandos $-\mathrm{y}$ no necesariamente políticos- integrados por un máximo de 6 o 10 miembros, y sólo excepcionalmente parecen haberse reclutado mediante solidaridades verticales. A pesar de la desestabilización ocasional que suponían para la vida pública, lo cierto es que el poder institucional, representado por el municipio y respaldado por la monarquía, no se vio seriamente amenazado por las facciones. Y en general, la mayoría de los bandos, integrados por vecinos comunes, constituían una forma más de una violencia estructural que sin duda emanaba de las tensiones cotidianas de la comunidad local, sin vinculación directa con la vida política de la villa.

$$
* \quad * \quad *
$$

A partir de los registros del tribunal del justicia, puede esbozarse un modelo de violencia que, por la identidad colectiva de sus protagonistas, resulta coherente con una comunidad local dotada de funciones urbanas, pero formada mayoritariamente por labradores propietarios que daban una tonalidad rural a su entramado socioeconómico. Se trataba, en general, de una violencia cotidiana de «baja intensidad», donde el homicidio no era frecuente y el derramamiento de sangre relativamente ocasional, a pesar de la facilidad con que se accedía a las armas incluidas las de guerra. Lo más significativo era la diferencia entre el perfil social de los agresores y el de sus víctimas. Vecinos de todas las condiciones se veían implicados en hechos violentos, aunque, considerados globalmente, los atacantes solían pertenecer a un medio socio-profesional y político de nivel superior que el de los agredidos. Los labradores eran claramente mayoritarios en los dos lados, lo cual, en un principio, traducía su predominio demográfico en la villa. Pero es significativo que los sectores más débiles — las mujeres como género y los criados y marginales - fuesen sobre todo víctimas de la violencia, ejercida por parientes y vecinos mejor situados socialmente. Los agresores, en conjunto, tenían un nivel de riqueza superior al de las víctimas y una mayor participación en el gobierno municipal. Sin embargo, no eran los prohombres situados en la cúspide de la sociedad local — mercaderes y profesionales liberales-, que unían a su prestigio profesional la riqueza y el control de los principales cargos políticos, quienes mostraban comportamientos más agresivos, sino los sectores medios-altos donde se situaban los labradores acomodados. De hecho, la presencia de campesinos ricos - los kulaks de cierta tradición historiográfica - entre los vecinos violentos era un hecho habitual en las comunidades rurales inglesas de los siglos XIII y XIV ${ }^{102}$. La opción por la violencia, en estos casos, no constituía el último recurso ante el descrédito de

${ }^{102}$ Cf. RaZI, Zvi: Life, Marriage and Death in a Medieval Parish: Economy, Society and Demography in Halesowen, 1270-1400, Cambridge, 1980, págs. 77-78 y, del mismo autor, «Family, land and the village community in later medieval England», en AstON, T. H. (ed.): Landlords, Peasants and Politics in Medieval England, Cambridge, 1987, págs. 360-393. 
los tribunales, ya que las agresiones no eran una alternativa a las reclamaciones judiciales y los arbitrajes, sino que los incidentes violentos calculados formaban parte de una estrategia global donde se recurría también a las demandas legales y las negociaciones. Un ataque podía ser incluso la manera de dar publicidad a la reclamación de un derecho, que posteriormente se seguía por la vía judicial ${ }^{103}$. No parece, sin embargo, que éste fuese el sentido de la mayoría de las violencias cometidas en Castellón durante el siglo XV. De entrada, eran muy minoritarios los ataques premeditados y se efectuaban tratando de evitar la presencia de testigos, mientras que esto era lo que sí hacían algunos agresores ingleses en el contexto de una violencia ritualizada y, por tanto, pública. Por otra parte, los casos documentados en la villa valenciana eran denunciados por las víctimas, de manera que difícilmente puede pensarse que la publicidad del ataque dañase su reputación — la fama publica, más importante en el derecho consuetudinario anglosajón que en el romanista mediterráneo- o que jugase a favor de la reclamación legal del agresor. Todo parece indicar que la violencia surgía de manera espontánea, y sólo excepcionalmente se calculaba como una represalia o un intento de imponer una resolución del conflicto al margen de la ley, atemorizando al adversario o incluso eliminándolo ${ }^{104}$.

$\mathrm{Al}$ analizar los factores implicados en la violencia, se puede hacer hincapié en el sistema de valores que legitimaba el uso de la fuerza para resolver los conflictos, dejando en un segundo plano las raíces sociales de la conflictividad cotidiana. En este sentido, la violencia sería un lenguaje codificado que puede interpretarse en un contexto básicamente cultural, el de las «mentalidades» o del imaginario colectivo, donde la noción del honor, de la virilidad e incluso de los valores caballerescos configuraba un modelo de «sociabilidad violenta». No cabe duda de que esta aproximación, que podría denominarse «antropológica», permite analizar una dimensión clave de los comportamientos violentos, pero tiende a aislarlos del resto de manifestaciones de la conflictividad que se generaba en una comunidad local. La agresión solía ser un episodio de un enfrentamiento que podía manifestarse, simultáneamente, mediante reclamaciones legales u otras acciones informales de carácter no violento. Además, para esta-

${ }^{103}$ Cf. SCHOfIELD, Phillipp: «Peasants and the manor court: gossip and litigation in a Suffolk village at the close of the thirteenth century», Past and Present, 159 (mayo 1998), págs. 3-42, donde se trata un caso en que el atacante requiere la presencia de testigos que den publicidad del hecho violento. Esta idea del uso de la violencia ritual como una forma de reclamar públicamente un derecho por parte del agresor, en la Italia del siglo XII, es desarrollada por WICKHAM, Chris: «Ecclesiastical Dispute and Lay Community: Figline Valdarno in the Twelfth Century», Mélanges de l'École Francaise de Rome. Moyen Âge, 108 (1996), págs. 7-93.

${ }^{104}$ En el caso castellano de finales de la Edad Media, el recurso a la justicia parece ser también predominante sobre la violencia, aunque las dos opciones no se excluían mutuamente. También aquí, los «poderosos» en cada contexto determinado —el señor respecto al campesino, el marido respecto a la mujer, el cristiano frente al judío o musulmán, etc.- tendían a protagonizar los actos violentos, según la síntesis de VAL VALDIVIeSO, M. Isabel del: "Conflictividad...», art. cit., págs. 1048-1049. 
blecer las relaciones entre un modelo de violencia y la sociedad concreta de donde surgía, apelar a unos valores prácticamente ahistóricos como el «honor mediterráneo» o quizá más acotados como el «código caballeresco» puede resultar insuficiente, ya que si estos valores eran hegemónicos difícilmente pueden explicar las diferencias de comportamiento de los diversos grupos sociales en torno al fenómeno de la violencia. Cuando en marzo de 1441, en un camino solitario, el labrador Miquel Cireró llamaba «vieja puta» a la viuda Sibília Valentí, la amenazaba diciéndole que si fuese un hombre la trataría de otra manera y la golpeaba con el asta de una lanza, el agresor estaba haciendo uso de una violencia verbal y física que deja translucir unos determinados valores sobre los géneros femenino y el masculino, y la vejez como grupo de edad. El rudo Miquel Cireró, sin saberlo, utilizaba un lenguaje simbólico que - no hay que olvidarlo- tenía unos referentes que no eran sólo el imaginario colectivo, sino una realidad externa y material. La causa de este enfrentamiento era el trazado de una acequia, y una acequia, en última instancia, era una canalización de riego que podía ser vital para el funcionamiento de una explotación campesina. Es obvio que la existencia de la disputa no implicaba necesariamente que Cireró recurriese a la violencia, pero el sentido de sus actuaciones no podría explicarse meramente en términos de honor o de valores, sin tener en cuenta la importancia que podía tener para un labrador, en aquella comunidad concreta, disponer de agua de riego. Por otra parte, la agresión de Cireró se produjo en el contexto de un enfrentamiento donde tuvieron lugar otros episodios de carácter judicial. Unas semanas antes del incidente violento, Miquel Cireró, a instancia de la viuda Sibília Valentí, ya había recibido del justicia la orden de no realizar ninguna modificación en la acequia en litigio. Dos días después del ataque, el mismo justicia mandaba a Llorenç y Joan Valentí, parientes sin duda de la viuda, que no hiciesen daño ni injuriasen a Cireró, lo cual indica que la parte inicialmente agredida tampoco descartaba el recurso a la violencia, y, por su parte, aquél tuvo que dar garantías de que no atacaría a los Valentí105. Finalmente, el caso se resolvió —al menos a nivel judicial — con una sentencia contraria a Miquel Cirerón ${ }^{106}$.

La tipología de los conflictos que podían derivar en conductas agresivas, es relevante para tratar de establecer la coherencia entre la violencia y la sociedad que la generaba. En este sentido, en la misma fuente que aporta información sobre los actos violentos, los libros del justicia, también se registran los pleitos civiles que permiten esbozar las rivalidades — no necesariamente violentasque enfrentaban a los vecinos de la villa. Se trata de 272 casos diferentes - documentados mediante denuncias, sentencias, declaraciones de testigos, mandatos

105 De hecho, en los conflictos de ámbito local, la venganza y otras actitudes violentas no eran incompatibles con el recurso a las instituciones judiciales, como señala el estudio sobre Marsella de SMAIL, Daniel L., «Common violence...», art. cit., i la reflexión general de ALFONSO, Isabel, «Los nombres de la violencia...», art. cit., págs. 702-703.

106 AMC, CJ, 24 de enero, 20 y 29 de marzo, y 8 de abril de 1441, respectivamente. 
ejecutorios y otras diligencias procesales - que corresponden a 25 años repartidos entre 1426 y 1495 . Un $37 \%$ de ellos hacen referencia a la propiedad de la tierra, con una casuística que abarcaba desde pleitos por acequias, caminos y lindes de campos, a daños causados por el ganado. Del resto de casos, destacan los asuntos relativos al trabajo asalariado $(20 \%)$-sobre todo disputas sobre jornales y soldadas de mozos, en buena parte agrícolas-y las reclamaciones de pequeñas deudas y censos enfitéuticos $(14 \%)$. Los pleitos referentes a herencias, dotes, tutelas y otras incidencias de la vida familiar (14\%) quedaban, así, por detrás de los motivados por la propiedad agraria y las actividades económicas. En conjunto, se trataba de unas rivalidades que surgían de las relaciones cotidianas en torno a una economía agraria donde la densidad de la ocupación de la tierra — sobre todo en la huerta - la atomización y dispersión de las parcelas, la complejidad de la red de acequias y caminos y la dificultad de integrar la ganadería, multiplicaban las ocasiones de conflicto. Y esto no sólo afectaba a los labradores, sino a la inmensa mayoría de vecinos - incluyendo a burgueses y artesanos- que poseían tierras. Hasta en una villa con claras funciones urbanas, el campo constituía una fuente destacada de enfrentamientos — quizá la más importante, con más de la mitad de los litigios-y, por tanto, era un factor de violencia potencial ${ }^{107}$.

La dimensión agraria de la realidad socioeconómica local justificaba el predomino de los labradores entre los agresores y los agredidos, y la tipología de los conflictos denunciados, ligados a las actividades económicas cotidianas, puede explicar el carácter estructural, endémico aunque normalmente de baja intensidad, de las formas habituales de la violencia. Lo que conviene aclarar es por qué, en líneas generales, existía una diferencia de nivel social y económico entre los vecinos violentos y sus víctimas. El hecho de que las manifestaciones verticales de la violencia, tal como se han identificado en la villa de Castellón, tuviesen un sentido descendente no constituye una situación excepcional. En las comunidades rurales inglesas la violencia no solía ser el «arma de los débiles», sino que allí, como en otras sociedades campesinas, las formas de resistencia cotidiana contra los poderosos no eran ataques o rebeliones abiertas, sino actos de sabotaje y otras formas de presión clandestina o difusa ${ }^{108}$. Todo hace pensar que, ante un conflic-

107 Sobre el trasfondo agrario de los conflictos violentos identificados en una villa valenciana, en los primeros momentos de la colonización catalano-aragonesa, cf. TORRÓ, Josep: La formació d'un espai feudal. Alcoi de 1245 a 1305, Valencia, 1992, págs. 249-254. Para una evocadora aproximación a las formas de la violencia rural, en este caso más centrada en una lectura «antropológica» del conflicto, puede verse el libro de GARCIA-Oliver, Ferran: La vall de les sis mesquites. El treball $i$ la vida a la Valldigna medieval, Valencia, 2003, págs. 163-191.

108 Cf. SCHOfIELD, Phillip: «Peasants...», art. cit. Sobre la resistencia no violenta de los campesinos pobres, es sugestivo el estudio, basado en el caso local de Sedaka, una aldea malaya contemporánea, de ScOTT, James C.: Weapons of the Weak. Everyday Forms of Peasant Resistance, New Haven, 1985. En general, en la Edad Media valenciana no se produjeron levantamientos campesinos antiseñoriales comparables a los de la Corona de Castilla estudiados por BARROs, Carlos: Mentalidad justiciera de los 
to con una personaje situado en una posición superior dentro de la jerarquizada comunidad local, los campesinos y otros vecinos de la villa tenderían a abstenerse de recurrir a la violencia. De hecho tenían todas las de perder, ya que esta superioridad podía manifestarse en una mayor capacidad tanto de apelar a las instituciones judiciales —incluso de manipularlas, como hemos visto_-, como de responder a la agresión con la violencia de sus numerosos familiares y partidarios. En estas condiciones, las conductas agresivas tenían menos cortapisas cuando se podían aplicar sobre vecinos más débiles en todos los sentidos ${ }^{109}$. Es cierto que una mujer podía golpear a un sayón que le reclamaba un pago, pero es más dudoso que agrediese al propio justicia, el cargo de mayor dignidad pública que era ejercido por ricos mercaderes y notarios. En cambio, sí que se han documentado ataques de vecinos acomodados a este oficial, como los golpes que, en 1445, propinó el eclesiástico Bonanat Capcir, miembro de una destacada familia local, al justicia que pretendía embargarle algunos bienes de su domicilio ${ }^{110}$. Lo habitual, pues, sería que, ante un contrincante de mayor nivel socioeconómico, los valores viriles y caballerescos que legitimaban el uso de la violencia se dejasen de lado. Pero el uso de la fuerza, incluso desproporcionado, encontraba menos barreras al dirigirse hacia abajo: un hombre adulto podía golpear a una anciana viuda o a una criada adolescente, los casos más extremos de vulnerabilidad social. Volviendo a Miquel Cireró, es posible que si, en lugar de haberse tropezado con la viuda Valentí lo hubiese hecho con sus parientes Llorenç o Joan, el enfrentamiento no se hubiera producido en los mismos términos —insultos y vejaciones_-, sino que, de haber estallado, habría tenido consecuencias más graves. Lo que es prácticamente seguro es que, si los adversarios de Miquel Cireró hubieran sido prohombres como los mercaderes Francesc y Joan Miquel, con esbirros dispuestos a matar y capaces de mediatizar el funcionamiento de la justicia, este labrador modesto habría evitado las provocaciones violentas. Como «débil» que era tendría que haber buscado otras armas... Y es que la violencia cotidiana que surgía villas como ésta, con su sentido descendente, confirmaba y reforzaba las jerarquías internas de la sociedad local.

irmandiños, siglo XV, Madrid, 1990, o CABRERA, Emilio y MOROS, Andrés: Fuenteovejuna. La violencia antiseñorial en el siglo XV, Barcelona, 1991.

${ }_{109}$ Los kulaks ingleses del periodo posterior a la Peste Negra, en comparación con la época anterior, tendían a agredir menos a sus vecinos, mientras que continuaban atacando con igual intensidad a sus parientes. Este comportamiento diferente se ha interpretado como el resultado de la contención física de los campesinos acomodados ante el conflicto con sus vecinos (para salvaguardar una necesaria ayuda mutua), mientras que este factor de autocontrol no actuaría dentro del grupo familiar, cf. RAZI, Zvi: «Family, land and the village community...», art. cit., págs. 390-391. En el caso de Castellón, la contención de los vecinos relativamente más débiles tendría que ver con el reconocimiento del riesgo que suponía enfrentarse abiertamente a vecinos más poderosos en términos legales y sociales.

110 AMC, CJ, 8 de noviembre de 1445. Hay que decir que Bonanat Capcir, no contento con la humillante agresión, amenazó al justicia con hacerlo encarcelar por el lugarteniente de gobernador, que era primo hermano suyo. 